\title{
Synthesis of Cyclic Peptidomimetics from Aldol Building Blocks
}

\author{
Sanjita Sasmal, ${ }^{a}$ Armin Geyer, ${ }^{b}$ and Martin E. Maier ${ }^{a, *}$
}

${ }^{a}$ Institut für Organische Chemie, Universität Tübingen, Auf der Morgenstelle 18, D-72076 Tübingen, Germany and ${ }^{b}$ Institut für Organische Chemie, Universität Regensburg, D-93040 Regensburg, Germany

martin.e.maier@uni-tuebingen.de

\section{Supporting Information}

Table of contents

Experimental Section

Signal assignment for the trans-Isomer 12aa_ab_E

ROESY spectrum of the trans-Isomer 12aa_ab_E

Signal assignment for the cis-Isomer 12aa_ab_Z

ROESY spectrum of the cis-Isomer 12aa_ab_Z

Proton and carbon spectra of new compounds page

S2

$\mathrm{S} 10$

S11

S12

S13

S14 


\section{Experimental Section}

General. ${ }^{1} \mathrm{H}$ and ${ }^{13} \mathrm{C}$ NMR: Bruker Avance 400, Bruker AMX 600, spectra were recorded in $\mathrm{CDCl}_{3}$ except for the ROESY spectra of 12aa_ab which were measured in DMSO- $\mathrm{d}_{6}$; chemical shifts are calibrated to the residual proton and carbon resonance in $\mathrm{CDCl}_{3}$ (7.25 ppm, $\left.77.00 \mathrm{ppm}\right)$. EI-MS; Finnigan Triple-Stage-Quadrupol (TSQ-70). HR-MS (EI): modified AMD Intectra MAT 711 A. HRMS (FT-ICR): BRUKER Daltonic APEX 2 with electronspray-ionization (ESI). Optical rotation: JASCO Polarimeter P-1020. IR: Jasco FT/IR-430 spectrometer. ATR-FT-IR: Bruker Vector 22. GCMS: HP 6890 Series GC system with 5973 mass selective detector and 7683 Series injector. Flash chromatography: J. T. Baker silica gel 43-60 $\mu \mathrm{m}$. Thin-layer chromatography Machery-Nagel Polygram Sil G/UV ${ }_{254}$. Solvents were distilled prior to use; petroleum ether with a boiling range of 40$60{ }^{\circ} \mathrm{C}$ was used. Merrifield resin HL (100-200 mesh), loading $1.6 \mathrm{mmol} \mathrm{g}$ from Novabiochem was used.

\section{General procedures for solution phase reactions}

\section{General procedure for aldol reaction}

To a solution of the oxazolidinone derivative $3 \mathbf{a}(16.7 \mathrm{mmol})$ in dichloromethane $(60 \mathrm{~mL})$ at $0{ }^{\circ} \mathrm{C}$

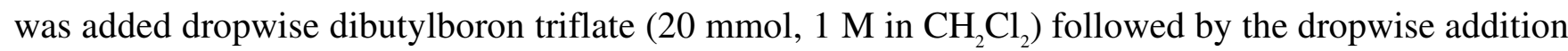
of Hünig's base $(21.7 \mathrm{mmol})$. The reaction mixture was stirred for $1 \mathrm{~h}$ at $0{ }^{\circ} \mathrm{C}$ and then cooled to -78 ${ }^{\circ} \mathrm{C}$. Thereafter, freshly distilled aldehyde $4 \mathbf{a}(25.1 \mathrm{mmol})$ was added dropwise and the reaction mixture stirred at $-78{ }^{\circ} \mathrm{C}$ for $1 \mathrm{~h}$. The reaction mixture was warmed up to room temperature over a period of $1 \mathrm{~h}$ and stirred at the same temperature for $2 \mathrm{~h}$. Then it was cooled to $0{ }^{\circ} \mathrm{C}$ and a mixture of $\mathrm{pH} 7$ phosphate buffer $(20 \mathrm{~mL})$ and methanol $(60 \mathrm{~mL})$ was added. The resulting cloudy solution was then treated with a mixture of methanol and $30 \% \mathrm{H}_{2} \mathrm{O}_{2}(2: 1,60 \mathrm{~mL})$ via syringe at such a rate so as to keep the temperature below $10{ }^{\circ} \mathrm{C}$. The solution was stirred for $1 \mathrm{~h}$ and the volatile materials were removed with a rotary evaporator. The resulting mixture was diluted with ethyl acetate and the organic layer was washed with $5 \%$ aqueous $\mathrm{HCl}$ solution, aqueous $\mathrm{NaHCO}_{3}$ solution, brine, dried $\left(\mathrm{Na}_{2} \mathrm{SO}_{4}\right)$, filtered, 
and concentrated to give the crude product which was purified by flash column chromatography using $30 \%$ ethyl acetate in petroleum ether as an eluent to provide the aldol adduct 5aa in $82 \%$ yield.

\section{General procedure for allylation}

To a solution of the aldol product 5aa $(2.7 \mathrm{mmol})$ in dichloromethane $(3 \mathrm{~mL})$ was added the trichloroacetimidate $6(5.4 \mathrm{mmol})$, dissolved in cyclohexane $(6 \mathrm{~mL})$. The reaction mixture was cooled to $0{ }^{\circ} \mathrm{C}$ and triflic acid $(100 \mu \mathrm{l})$ was added to it dropwise. The reaction mixture was allowed to stir at room temperature overnight. The solid was filtered off and the filtrate washed with saturated $\mathrm{NaHCO}_{3}$ solution, water, brine, dried $\left(\mathrm{Na}_{2} \mathrm{SO}_{4}\right)$, filtered and concentrated in vacuo. The crude product was purified by flash column chromatography using $12 \%$ ethyl acetate in petroleum ether as eluent to afford the O-allyl derivative $7 \mathbf{a a}(68 \%$ yield).

\section{General procedure for the preparation of the acids 8}

A solution of the O-allyl compound 7aa $(1.7 \mathrm{mmol})$, dissolved in a mixture of THF and $\mathrm{H}_{2} \mathrm{O}(3: 1,20$ $\mathrm{mL})$ was treated dropwise at $0{ }^{\circ} \mathrm{C}$ with $30 \% \mathrm{H}_{2} \mathrm{O}_{2}(9.2 \mathrm{mmol})$ and a solution of lithium hydroxide $(6.7$ mmol) in water $(3 \mathrm{~mL})$. The reaction mixture was allowed to stir at $0{ }^{\circ} \mathrm{C}$ for $1 \mathrm{~h}$ and at room temperature for $2.5 \mathrm{~h}$. The excess of $\mathrm{H}_{2} \mathrm{O}_{2}$ was quenched by the addition of of sodium sulfite $(1 \mathrm{~g}$ in 5 $\mathrm{mL}$ of water). Most of the THF was removed with a rotavapor (water bath at $25-30{ }^{\circ} \mathrm{C}$ ) and the water layer was extracted with dichloromethane to remove the oxazolidinone. The aqueous layer was acidified with $1 \mathrm{M}$ aqueous $\mathrm{HCl}$ solution and extracted with ethyl acetate. The ethyl acetate layer was dried $\left(\mathrm{Na}_{2} \mathrm{SO}_{4}\right)$, filtered and concentrated to give the crude product which was purified by flash column chromatography using $30 \%$ ethyl acetate in petroleum ether as an eluent to provide the acid 8aa in $74 \%$ yield.

\section{General procedure for the preparation of the amines 9}

To a solution of the acid 8aa $(0.5 \mathrm{mmol})$ in dry acetonitrile $(3 \mathrm{~mL})$, triethylamine $(0.5 \mathrm{mmol})$ and diphenylphosphoryl azide $(0.5 \mathrm{mmol})$ was added and the reaction mixture was heated at $50{ }^{\circ} \mathrm{C}$ for 1.5 h. After cooling to room temperature, $1 \mathrm{~N}$ aqueous $\mathrm{HCl}$ solution $(3 \mathrm{~mL})$ was added and the reaction 
mixture refluxed overnight. The acetonitrile was evaporated and the aqueous layer neutralized with solid $\mathrm{NaHCO}_{3}$ and extracted with chloroform. The chloroform layer was dried $\left(\mathrm{Na}_{2} \mathrm{SO}_{4}\right)$, filtered, and concentrated to give the crude product which was purified by flash column chromatography (on triethylamine impregnated silica gel) using $5 \%$ methanol in chloroform as an eluent to give the required amine 9aa in 78\% yield. The silica gel was impregnated by making a slurry of the silica gel $(100 \mathrm{~g})$ in petroleum ether containing $5 \mathrm{~mL}$ of triethylamine. After cooling, the solvents are evaporated on the rotavapor.

\section{General procedure for amide coupling}

Ethyldiisopropylamine (DIPEA) $(0.72 \mathrm{mmol})$ was added to the mixture of amine 9 aa $(0.24 \mathrm{mmol})$, the acid 8aa $(0.24 \mathrm{mmol})$ and BOP $(0.29 \mathrm{mmol})$ in anhydrous acetonitrile $(3 \mathrm{~mL})$ at room temperature. After stirring at the same temperature for $1 \mathrm{~h}$ (monitored by TLC), brine was added, and the reaction mixture was extracted with ethyl acetate. The ethyl acetate layer was washed with $10 \%$ citric acid solution, water, brine, dried $\left(\mathrm{Na}_{2} \mathrm{SO}_{4}\right)$, filtered, and concentrated to give the crude product which was purified by flash column chromatography using $30 \%$ ethyl acetate in petroleum ether as an eluent to provide the amide 10aa_aa in 95\% yield.

\section{General procedure for ring closing metathesis}

To a solution of Grubb's catalyst $11(0.0045 \mathrm{mmol})$ in dry dichloromethane $(20 \mathrm{~mL})$ (degassed for $1 / 2$ h by argon bubbling), the amide derivative 10aa_aa $(0.09 \mathrm{mmol})$ in dry dichloromethane $(3 \mathrm{~mL})$ was added at room temperature. After stirring the reaction mixture for $5 \mathrm{~h}$, water was added. The organic layer was separated, washed with brine, dried $\left(\mathrm{Na}_{2} \mathrm{SO}_{4}\right)$, filtered, and concentrated to give the crude

product which was purified by flash column chromatography to give the pure products $\mathbf{1 2 a a} \_$aa_E and 12aa_aa_Z $\mathbf{Z}$ in a 3:1 ratio as colorless solids; combined yield $73 \%$.

\section{General procedures for solid phase reactions}


Washings of resin after the reaction was carried out using $5 \mathrm{~mL}$ of each solvent, agitating the resin suspension for $2 \mathrm{~min}$. The yield was calculated on the basis of the change in weight after each reaction. In most of the cases the reaction was monitored by ATR-FT-IR technique.

\section{General procedure for anchoring alcohol with Merrifield resin}

To a suspension of sodium hydride $(6.4 \mathrm{mmol})$ in dry DMF $(3 \mathrm{~mL})$ the alcohol $16(5.3 \mathrm{mmol})$, dissolved in DMF (10 mL), was added at room temperature and agitating was continued for $3 \mathrm{~h}$ at the same temperature. Then Merrifield resin $(1.11 \mathrm{~g}, 1.77 \mathrm{mmol})$ was added to the reaction mixture and it was agitated for 3 days. The resin was filtered and washed thoroughly with water, DMF, THF, DCM and dried overnight under vacuum to provide the loaded resin (95\% loading, measured by chlorine content).

\section{General procedure for removal of THP protecting group}

A suspension of the resin $\mathbf{1 8}$ in a mixture of dichloromethane and methanol $(1: 1,6 \mathrm{~mL})$, containing dioxane $(0.1 \mathrm{~mL})$ and $p$-TsOH $(8.86 \mathrm{mmol})$, was agitated for $3 \mathrm{~h}$. After filtration, the resin was washed with DCM, MeOH, DCM and dried overnight under vacuum to provide the deprotected alcohol 19 in $82 \%$ yield. The deprotection progress was monitored by removing aliquots $(20 \mu \mathrm{L})$ from the reaction solution after every hour, diluting the aliquots with $80 \mu \mathrm{L}$ of DCM and injecting a sample $(5 \mu \mathrm{L})$ into the $\mathrm{GC}$ at $50{ }^{\circ} \mathrm{C}$. Deprotection was judged complete when the ratio of the peak areas of methoxytetrahydropyran and dioxane was constant. ${ }^{1}$

\section{General procedure for preparation of imidate 20}

The loaded resin 19 was suspended in dry DCM $(6 \mathrm{~mL})$ and trichloroacetonitrile $(35.5 \mathrm{mmol})$ was added to it under argon atmosphere followed by agitation for 5 minutes. DBU (1.6 mmol) was added

${ }^{1}$ (a) Kuisle, O.; Quiñoá, E.; Riguera, R. J. Org. Chem. 1999, 64, 8063-8075. (b) Hermann, C.; Giammasi, C.; Geyer, A.; Maier, M. E. Tetrahedron 2001, 57, 8999-9010. 
dropwise to the suspension and the mixture was agitated for $3 \mathrm{~h}$. Then the resin was washed with DCM, DMSO, THF and DCM, dried overnight under vacuum to provide the imidate 20 in $78 \%$ yield.

\section{General procedure for the allylation of 20 with the aldol product 5}

The loaded resin 20 was washed with anhydrous THF (2 times) under nitrogen atmosphere to remove moisture, then it was suspended in anhydrous cyclohexane. Now the alcohol $\mathbf{5 b c}(3.6 \mathrm{mmol})$, dissolved in dry DCM (so that cyclohexane : dichloromethane $=1: 1$ ) was added to it followed by 5 minutes of shaking. Thereafter, $\mathrm{BF}_{3}{ }^{*} \mathrm{OEt}_{2}(5 \mu \mathrm{l}$ per $100 \mathrm{mg}$ of resin) was added and agitation was continued for $3 \mathrm{~h}$. The resin was washed with DCM, DMF, THF and DCM and dried overnight in vacuum to give the oxazolidinone derivative 21 in $65 \%$ yield.

\section{General procedure for hydrolysis}

The resin was suspended in a mixture of water and THF $(1: 3,6 \mathrm{~mL})$ followed by the addition of $\mathrm{LiOH}(21.3 \mathrm{mmol})$ and agitated for $24 \mathrm{~h}$. Then the solution was filtered off and the resin washed with water, DMF, THF, DCM and dried. Then the resin was suspended in $1 \mathrm{~N}$ aqueous $\mathrm{HCl}$ in $\mathrm{THF}$ and agitated at room temperature for $24 \mathrm{~h}$. Afterwards, the solution was filtered off and the resin washed with water, THF, DCM and dried overnight under vacuum to provide the acid 22 in $62 \%$ yield.

\section{General procedure for amide coupling}

The loaded resin 22 was suspended in DCM and amine 9aa (4.43 mmol), PyBroP (5.32 mmol) and DIEA (10.64 mmol) were added at room temperature. The resulting mixture was shaken at room temperature for $12 \mathrm{~h}$. Then the solution was filtered off and the resin washed with DMF, MeOH, DCM and dried overnight under vacuum to provide the amide 23 in $75 \%$ yield.

\section{General procedure for ring closing metathesis}

The loaded resin $\mathbf{2 3}$ was suspended in dry DCM and a solution of Grubb's catalyst 11 (0.088 mmol) in DCM was added to it under nitrogen atmosphere and it was agitated for $36 \mathrm{~h}$ at room temperature. Then the solution was filtered and the filtrate concentrated and subjected to flash column chromatography yielding the product $\mathbf{1 2 b c \_ a a ~ ( c i s ~ a n d ~ t r a n s ~ i s o m e r ~ i n ~} 1: 3$ ratio) in $30 \%$ yield. 
$[\alpha]_{\mathrm{D}}^{27}+55.9^{\circ}\left(\mathrm{c} 1.73, \mathrm{CH}_{2} \mathrm{Cl}_{2}\right) ;{ }^{1} \mathrm{H} \mathrm{NMR}\left(400 \mathrm{MHz}, \mathrm{CDCl}_{3}\right): \delta 7.19-7.36(\mathrm{~m}, 10 \mathrm{H}), 4.68$ (dddd, $J=3.3$, 7.1, 9.6, 10.6 Hz, 1H), $4.19(\mathrm{~m}, 2 \mathrm{H}), 3.97(\mathrm{ddd}, J=3.4,3.5,6.3 \mathrm{~Hz}, 1 \mathrm{H}), 3.75(\mathrm{dq}, J=2.8,7.1 \mathrm{~Hz}$, 1H), $3.24(\mathrm{dd}, J=3.3,13.4 \mathrm{~Hz}, 1 \mathrm{H}), 2.79(\mathrm{~m}, 4 \mathrm{H}), 1.90(\mathrm{~m}, 1 \mathrm{H}), 1.71(\mathrm{~m}, 1 \mathrm{H}), 1.28(\mathrm{~d}, J=7.1 \mathrm{~Hz}$, $3 \mathrm{H}) ;{ }^{13} \mathrm{C} \mathrm{NMR}\left(100 \mathrm{MHz}, \mathrm{CDCl}_{3}\right): \delta 177.5,152.9,141.7,134.9,125.8-129.4$ (6 lines), 70.5, 66, 54.9, 42.2, 37.7, 35.4, 32.1, 10.5; IR (neat): 3513 (br), 2940, 1779, 1694, 1386, $1211 \mathrm{~cm}^{-1}$; EI-MS (m/z): 367 $\left[\mathrm{M}^{+}\right], 244,234,178,117,91$.

(4R)-3-[(2R,3S)-3-(Allyloxy)-2-methyl-5-phenylpentanoyl]-4-benzyl-1,3-oxazolidin-2-one (7bb). $[\alpha]_{\mathrm{D}}^{27}+72.5^{\circ}\left(\mathrm{c} 0.52, \mathrm{CH}_{2} \mathrm{Cl}_{2}\right) ;{ }^{1} \mathrm{H} \mathrm{NMR}\left(400 \mathrm{MHz}, \mathrm{CDCl}_{3}\right): \delta$ 7.16-7.36 (m, 10H), 5.88-5.95 (m, $\left.1 \mathrm{H}\right)$, 5.15-5.30 (m, 2H), $4.61(\mathrm{~m}, 1 \mathrm{H}), 4.01-4.16(\mathrm{~m}, 5 \mathrm{H}), 3.61(\mathrm{ddd}, J=4.1,5.6,7.8 \mathrm{~Hz}, 1 \mathrm{H}), 3.29(\mathrm{dd}, J=$ 3.3, $13.4 \mathrm{~Hz}, 1 \mathrm{H}), 2.74-2.86(\mathrm{~m}, 2 \mathrm{H}), 2.63(\mathrm{~m}, 1 \mathrm{H}), 1.81-1.96(\mathrm{~m}, 2 \mathrm{H}), 1.26(\mathrm{~d}, J=6.8 \mathrm{~Hz}, 3 \mathrm{H}) ;{ }^{13} \mathrm{C}$ NMR (100 MHz, $\left.\mathrm{CDCl}_{3}\right): \delta$ 175.1, 153.1, 142.0, 135.3, 134.9, 125.7-129.4 (6 lines), 116.9, 79.9, 71.5, 65.9, 55.7, 41, 37.7, 33.7, 31.9, 12.9; IR (neat): 2929, 1779, 1694, 1383, $1209 \mathrm{~cm}^{-1}$; EI-MS (m/z): 408 $[\mathrm{M}+1]^{+}, 349,244,172,91$.

(2R, 3S)-3-(Allyloxy)-2-methyl-5-phenylpentanoic acid (8bb). $[\alpha]_{\mathrm{D}}{ }^{24}+35.1^{\circ}\left(\mathrm{c} 0.26, \mathrm{CH}_{2} \mathrm{Cl}_{2}\right) ;{ }^{1} \mathrm{H}$ NMR (400 MHz, $\left.\mathrm{CDCl}_{3}\right): \delta 7.11-7.31(\mathrm{~m}, 5 \mathrm{H}), 5.92(\mathrm{~m}, 1 \mathrm{H}), 5.23(\mathrm{~m}, 2 \mathrm{H}), 4.06(\mathrm{tdq}, J=1.5,5.8,12.4$ $\mathrm{Hz}, 2 \mathrm{H}), 3.66(\mathrm{dt}, J=4.8,9.6 \mathrm{~Hz}, 1 \mathrm{H}), 2.6-2.84(\mathrm{~m}, 3 \mathrm{H}), 1.86(\mathrm{~m}, 2 \mathrm{H}), 1.20(\mathrm{~d}, J=7.1 \mathrm{~Hz}, 3 \mathrm{H}) ;{ }^{13} \mathrm{C}$ NMR $\left(100 \mathrm{MHz}, \mathrm{CDCl}_{3}\right): \delta 179.4,141.6,134.4,128.4,128.3,125.9,117.4,79.5,71.4,42.7,33.5$, 31.8, 11.7; IR (neat): 3300, 2944, 1704, $1455 \mathrm{~cm}^{-1}$; EI MS (m/z): 248 [M+1, 230, 190, 117, 91.

(4R)-4-Benzyl-3-[(2S,3R)-2-benzyl-3-hydroxy-5-phenylpentanoyl]-1,3-oxazolidin-2-one (5ab). $[\alpha]_{\mathrm{D}}^{22}+42.5^{\circ}\left(\mathrm{c} 1.35, \mathrm{CH}_{2} \mathrm{Cl}_{2}\right) ;{ }^{1} \mathrm{H}$ NMR $\left(400 \mathrm{MHz}, \mathrm{CDCl}_{3}\right): \delta$ 7.18-7.31 (m, 13H), 6.94-6.96 (m, 2H), 4.57-4.63 (m, 2H), $4.08(\mathrm{t}, J=8.33 \mathrm{~Hz}, 1 \mathrm{H}), 3.97-4.00(\mathrm{~m}, 2 \mathrm{H}), 3.14(\mathrm{dd}, J=10.6,13.6 \mathrm{~Hz}, 1 \mathrm{H}), 3.02$ (dd, $J=5.3,13.4 \mathrm{~Hz}, 1 \mathrm{H}), 2.92(\mathrm{ddd}, J=5.5,9.3,14.4 \mathrm{~Hz}, 1 \mathrm{H}), 2.87(\mathrm{dd}, J=3.8,13.9 \mathrm{~Hz}, 1 \mathrm{H}), 2.7$ (ddd, $J=7.3,9.4,13.9 \mathrm{~Hz}, 1 \mathrm{H}), 2.16(\mathrm{dd}, J=9.6,13.6 \mathrm{~Hz}, 1 \mathrm{H}), 1.85-2.00(\mathrm{~m}, 2 \mathrm{H}) ;{ }^{13} \mathrm{C} \mathrm{NMR}(100$ $\left.\mathrm{MHz}, \mathrm{CDCl}_{3}\right): \delta 175,153.4,141.7,138.6,135.1,125.9-129.4$ (8 lines), 71.7, 65.7, 54.9, 49.2, 37.2, 
35.4, 33.3, 32.3; IR (neat): 3499, 3026, 2924, 1779, 1694, 1390, $1211 \mathrm{~cm}^{-1}$; EI-MS (m/z): 444 [M + $1]^{+}, 426,399,310,105,91$.

(4R)-3-[(2S,3R)-3-(Allyloxy)-2-benzyl-5-phenylpentanoyl]-4-benzyl-1,3-oxazolidin-2-one (7ab). $[\alpha]_{\mathrm{D}}^{27}+60.9^{\circ}\left(\mathrm{c} 2.09, \mathrm{CH}_{2} \mathrm{Cl}_{2}\right) ;{ }^{1} \mathrm{H} \mathrm{NMR}\left(400 \mathrm{MHz}, \mathrm{CDCl}_{3}\right): \delta 7.17-7.31(\mathrm{~m}, 13 \mathrm{H}), 6.97(\mathrm{~m}, 2 \mathrm{H}), 5.92$ (dddd, $J=5.6,5.6,10.6,17.1 \mathrm{~Hz}, 1 \mathrm{H}), 5.15-5.28(\mathrm{~m}, 2 \mathrm{H}), 4.8(\mathrm{ddd}, J=5.3,5.3,10.6 \mathrm{~Hz}, 1 \mathrm{H}), 4.58$ (dddd, $J=2.9,7.6,9.8,11.9 \mathrm{~Hz}, 1 \mathrm{H}), 3.95-4.17(\mathrm{~m}, 4 \mathrm{H}), 3.60(\mathrm{ddd}, J=3.3,5.3,8.6 \mathrm{~Hz}, 1 \mathrm{H}), 3.09(\mathrm{dd}$, $J=10.1,13.4 \mathrm{~Hz}, 1 \mathrm{H}), 2.87-2.99(\mathrm{~m}, 3 \mathrm{H}), 2.62(\mathrm{ddd}, J=6.8,9.9,16.7 \mathrm{~Hz}, 1 \mathrm{H}), 2.32(\mathrm{dd}, J=9.3,13.6$ $\mathrm{Hz}, 1 \mathrm{H}), 1.88-2.04(\mathrm{~m}, 2 \mathrm{H}) ;{ }^{13} \mathrm{C} \mathrm{NMR}\left(100 \mathrm{MHz}, \mathrm{CDCl}_{3}\right): \delta 173.7,153,141.9,138.7,135.2,134.7$, 125.8-129.3 (8 lines), 117.2, 79.7, 71.4, 65.5, 55.5, 47.1, 37.3, 34.9, 33.6, 32.1; IR (neat): 3026, 1779, 1694, 1385, $1100 \mathrm{~cm}^{-1}$; EI-MS (m/z): $484[\mathrm{M}+1]^{+}, 426,399,310,105,91$.

(2S,3R)-3-(Allyloxy)-2-benzyl-5-phenylpentanoic acid (8ab). $[\alpha]_{\mathrm{D}}^{23}+37.7^{\circ}\left(\mathrm{c} 1.58, \mathrm{CH}_{2} \mathrm{Cl}_{2}\right) ;{ }^{1} \mathrm{H}$ NMR (400 MHz, $\left.\mathrm{CDCl}_{3}\right): \delta 7.11-7.29(\mathrm{~m}, 2 \mathrm{H}), 5.91(\mathrm{dddd}, J=5.8,5.8,10.3,16.2 \mathrm{~Hz}, 1 \mathrm{H}), 5.17-5.28$ (m, 2H), 3.98-4.07 (dtABq, $J=1.3,5.8,12.4 \mathrm{~Hz}, 2 \mathrm{H}), 3.57(\mathrm{ddd}, J=5.1,5.1,6.8 \mathrm{~Hz}, 1 \mathrm{H}), 2.99-3.04$ (m, 2H), $2.65(\mathrm{ddd}, J=8.6,13.9,16.2 \mathrm{~Hz}, 1 \mathrm{H}), 1.93(\mathrm{~m}, 2 \mathrm{H}) ;{ }^{13} \mathrm{C} \mathrm{NMR}\left(100 \mathrm{MHz}, \mathrm{CDCl}_{3}\right): \delta 178.2$, 141.5, 138.9, 134.2, 125.9-128.7 (5 lines), 117.6, 78.4, 70.9, 50.6, 33.8, 33.2, 31.5; IR (neat): 3300, 3026, 1707, $862 \mathrm{~cm}^{-1}$; EI-MS (m/z): 324 [M+], 306, 266, 175, 131, 117, 91.

(2S,3R)-3-(Allyloxy)-1,5-diphenyl-2-pentanamine (9ab). $[\alpha]_{\mathrm{D}}{ }^{24}+10.7^{\circ}\left(\mathrm{c} \quad 0.47, \mathrm{CH}_{2} \mathrm{Cl}_{2}\right) ;{ }^{1} \mathrm{H} \mathrm{NMR}$ $\left(400 \mathrm{MHz}, \mathrm{CDCl}_{3}\right): \delta$ 7.10-7.29 (m, $\left.10 \mathrm{H}\right), 5.87-5.97(\mathrm{~m}, 1 \mathrm{H}), 5.13-5.26(\mathrm{~m}, 2 \mathrm{H}), 3.92-4.06(\mathrm{dddt}, J=$ 5.5, 12.6, 18.3, 1.3, 2H), 3.20-3.30 (m, 2H), 2.5-2.86 (m, 4H), 1.78-2.00 (m, 2H); ${ }^{13} \mathrm{C} \mathrm{NMR} \mathrm{(100} \mathrm{MHz,}$ $\left.\mathrm{CDCl}_{3}\right): \delta 142.1,139.0,135.0,129.1,128.5,128.4,126.3,125.8,116.8,81.2,70.9,54.3,39.1,31.4$, 31.0; IR (neat): 3371, 3025, 1495, 1453, $1075 \mathrm{~cm}^{-1}$; EI-MS (m/z): 296 [M + 1] , 204, 120, 91.

\section{(2S,3R)-3-(Allyloxy)-N-[(1R,2S)-2-(allyloxy)-1-benzyl-4-phenylbutyl]-2-methyl-5-}

phenylpentanamide (10bb_ab). $[\alpha]_{\mathrm{D}}^{23}+0.9537^{\circ}\left(\mathrm{c} 0.51, \mathrm{CH}_{2} \mathrm{Cl}_{2}\right) ;{ }^{1} \mathrm{H}$ NMR $\left(400 \mathrm{MHz}, \mathrm{CDCl}_{3}\right): \delta$ 7.14-7.30 (m, 15H), 6.44-6.46(d, $J=9 \mathrm{~Hz}, 1 \mathrm{H},), 5.82-5.90(\mathrm{~m}, 2 \mathrm{H}), 5.09-5.30(\mathrm{~m}, 4 \mathrm{H}), 4.52(\mathrm{~m}, 1 \mathrm{H})$, 3.93-4.05 (m, 4H), 3.40-3.44 (ddd, $J=3.6,5.3,7.3 \mathrm{~Hz}, 1 \mathrm{H}), 3.34(\mathrm{~m}, 1 \mathrm{H}), 2.57-2.92(\mathrm{~m}, 6 \mathrm{H}), 2.42-$ 
$2.48(\mathrm{ddd}, J=4.4,7,11.4,1 \mathrm{H}), 1.78-1.89(\mathrm{~m}, 4 \mathrm{H}), 1.02(\mathrm{~d}, J=6.8 \mathrm{~Hz}, 1 \mathrm{H}) ;{ }^{13} \mathrm{C}$ NMR $(100 \mathrm{MHz}$ $\left.\mathrm{CDCl}_{3}\right): \delta 173.3,141.9,141.7,138.3,134.9,134.5,128.9,128.2-128.3$ (5 lines), 126.2, 125.8, 125.7, 116.7, 116.5, 80.6, 79.9, 77.3, 77, 76.68, 70.85, 70.65, 51.1, 42.8, 35.6, 32.4, 32.3, 31.9, 31.8, 12.9; IR (neat): $\mathrm{cm}^{-1}$; EI-MS (m/z): $526[\mathrm{M}+1]^{+}, 434,350,131,120,91$.

\section{(2S,3R,6S,7R)-3-Benzyl-6-methyl-2,7-bis(2-phenylethyl)-1,8-dioxa-4-azacyclododec-10-en-5-one}

(12bb_ab). Z-isomer: $[\alpha]_{\mathrm{D}}^{23}+12.3^{\circ}\left(\mathrm{c} 0.79, \mathrm{CH}_{2} \mathrm{Cl}_{2}\right) ;{ }^{1} \mathrm{H}$ NMR $\left(400 \mathrm{MHz}, \mathrm{CDCl}_{3}\right): \delta$ 7.16-7.30 (m, $15 \mathrm{H}), 6.11-6.13(\mathrm{~d}, J=9.4 \mathrm{~Hz}, 1 \mathrm{H}), 5.82-5.88(\mathrm{~m}, 1 \mathrm{H}), 5.68-5.73(\mathrm{~m}, 1 \mathrm{H}), 4.44(\mathrm{t}, J=10.1 \mathrm{~Hz}, 1 \mathrm{H})$, $4.37(\mathrm{~m}, 1 \mathrm{H}), 4.27-4.32(\mathrm{dd}, J=5.1,14.6 \mathrm{~Hz}, 1 \mathrm{H}), 4.17-4.21(\mathrm{dd}, J=5.6,10.7 \mathrm{~Hz}, 1 \mathrm{H}), 4.03-4.08(\mathrm{dd}$, $J=4.5,14.1 \mathrm{~Hz}, 1 \mathrm{H}), 3.56(\mathrm{~m}, 1 \mathrm{H}), 3.31(\mathrm{~m}, 1 \mathrm{H}), 2.90-2.95(\mathrm{dd}, J=4.5,15.1 \mathrm{~Hz}, 1 \mathrm{H}), 2.57-2.86(\mathrm{~m}$, 6H), $2.46(\mathrm{~m}, 1 \mathrm{H}), 1.79-1.94(\mathrm{~m}, 4 \mathrm{H}), 0.96(\mathrm{~d}, J=7.2 \mathrm{~Hz}, 3 \mathrm{H}) ;{ }^{13} \mathrm{C} \mathrm{NMR}\left(100 \mathrm{MHz}, \mathrm{CDCl}_{3}\right): \delta 172.5$, 141.7, 141.6, 138.6, 130.0, 125.9-129.4 (9 lines), 83.6, 80.6, 68.9, 66.9, 52, 42.6, 34.5, 33.9, 32.8, $32.5,31.6,11.6$.

E-isomer: $[\alpha]_{\mathrm{D}}^{25}-74.9^{\circ}\left(\mathrm{c} 1.44, \mathrm{CH}_{2} \mathrm{Cl}_{2}\right) ;{ }^{1} \mathrm{H}$ NMR $\left(400 \mathrm{MHz}, \mathrm{CDCl}_{3}\right): \delta$ 7.13-7.36 (m, $\left.15 \mathrm{H}\right), 5.60-$ $5.67(\mathrm{~m}, 1 \mathrm{H}), 5.42-5.49(\mathrm{~m}, 1 \mathrm{H}), 5.09-5.11(\mathrm{~d}, J=7.8 \mathrm{~Hz}, 1 \mathrm{H}), 4.09-4.20(\mathrm{~m}, 3 \mathrm{H}), 3.72-3.76(\mathrm{dt}, J=$ $2.1,7 \mathrm{~Hz}, 1 \mathrm{H}), 3.52-3.58(\mathrm{dd}, J=8.9 \mathrm{~Hz}, 12.4 \mathrm{~Hz}, 1 \mathrm{H}), 3.42-3.47(\mathrm{dd}, J=9.2,12.7 \mathrm{~Hz}, 1 \mathrm{H}), 3.33-3.37$ (m, 1H), 2.99-3.03 (dd, $J=3.8,14.8 \mathrm{~Hz}, 1 \mathrm{H}), 2.67-2.86(\mathrm{~m}, 3 \mathrm{H}), 2.52-2.61(\mathrm{~m}, 2 \mathrm{H}), 2.20-2.26(\mathrm{dq}, J=$ 2.4, 7.3 Hz, 1H), 2.02-2.11 (m, 1H), 1.80-1.92 (m, 3H), 0.97-0.98 (d, $J=6.7 \mathrm{~Hz}, 3 \mathrm{H}) ;{ }^{13} \mathrm{C}$ NMR $(100$ $\mathrm{MHz}, \mathrm{CDCl}_{3}$ ): lines), 78.4, 77.4, 69.8, 67.7, 52.6, 41.8, 34.7, 33.1, 32.6, 32.2, 31.9, 8.9; IR (neat): 3340, 2925, 1650, 1532, 1456, $1096 \mathrm{~cm}^{-1}$; EI-MS (m/z): 498 [M + 1] $]^{+}$, 406, 218, 91; HRMS: Calcd. for $\mathrm{C}_{33} \mathrm{H}_{39} \mathrm{NO}_{3} 497.2929$, found 497.2911 . 
Signal assignment for the trans-Isomer 12aa_ab_E (DMSO, $600 \mathrm{MHz}, 300 \mathrm{~K})$. Geminal methylene groups (cf. 16) are labeled as lowfield (cf. 16) and highfield signal $\left(16^{\mathrm{h}}\right)$, respectively. The corresponding carbon atom appears two times in the table and is enclosed in brackets. $\mathrm{m}=$ multiplett, no coupling can be extracted.

\begin{tabular}{|c|c|c|c|c|}
\hline & $\delta{ }^{1} \mathbf{H}$ ppm & Integral & $\mathrm{J}$ & $\delta{ }^{13} \mathrm{C} \mathrm{ppm}$ \\
\hline 2 & 3.62 & 1 & $7.1 \mathrm{~Hz}, 1.9 \mathrm{~Hz}$ & 76.84 \\
\hline 3 & 3.82 & 1 & $8.7 \mathrm{~Hz}$ & 52.78 \\
\hline 5 & - & - & - & 171.26 \\
\hline 6 & 2.58 & 1 & $10.3 \mathrm{~Hz}$ & 47.78 \\
\hline 7 & 3.70 & 1 & $7.5 \mathrm{~Hz}, 2.1 \mathrm{~Hz}$ & 78.23 \\
\hline $9^{1}$ & 3.98 & 1 & $12.2 \mathrm{~Hz}, 4.9 \mathrm{~Hz}$ & 67.00 \\
\hline $9^{\text {h }}$ & 3.52 & 1 & $12.4 \mathrm{~Hz}, 9.5 \mathrm{~Hz}$ & $(67.00)$ \\
\hline 10 & 5.56 & 1 & $15.2 \mathrm{~Hz}, 9.7 \mathrm{~Hz}, 5.1 \mathrm{~Hz}$ & 131.93 \\
\hline 11 & 5.83 & 1 & $15.4 \mathrm{~Hz}, 9.8 \mathrm{~Hz}, 5.8 \mathrm{~Hz}$ & 131.93 \\
\hline $12^{1}$ & 4.09 & 1 & $11.9 \mathrm{~Hz}, 5.4 \mathrm{~Hz}$ & 67.94 \\
\hline $12^{\mathrm{h}}$ & 3.48 & 1 & $12.2 \mathrm{~Hz}, 9.6 \mathrm{~Hz}$ & $(67.94)$ \\
\hline 13 & 1.80 & 2 & $\mathrm{~m}$ & 33.66 \\
\hline 14 & 2.66 & 2 & $\mathrm{~m}$ & 31.94 \\
\hline $15^{1}$ & 2.84 & 1 & $14.9 \mathrm{~Hz}, 2.9 \mathrm{~Hz}$ & 31.80 \\
\hline $15^{\mathrm{h}}$ & 2.62 & 1 & $\mathrm{~m}$ & 31.80 \\
\hline $16^{1}$ & 2.99 & 1 & $14.6 \mathrm{~Hz}, 9.9 \mathrm{~Hz}$ & 28.55 \\
\hline $16^{\mathrm{h}}$ & 2.50 & 1 & $\mathrm{~m}$ & $(28.55)$ \\
\hline 17 & $1.49,1.78$ & 2 & $\mathrm{~m}$ & 24.20 \\
\hline 18 & 0.88 & 3 & $7.4 \mathrm{~Hz}$ & 10.53 \\
\hline
\end{tabular}

Ar-C: $125.2-142.03$ ppm, 12 signals

Ar-H: $6.95-7.30$ ppm, multiplett

N-H: $7.72 \mathrm{ppm}, J=7.2 \mathrm{~Hz}$ 

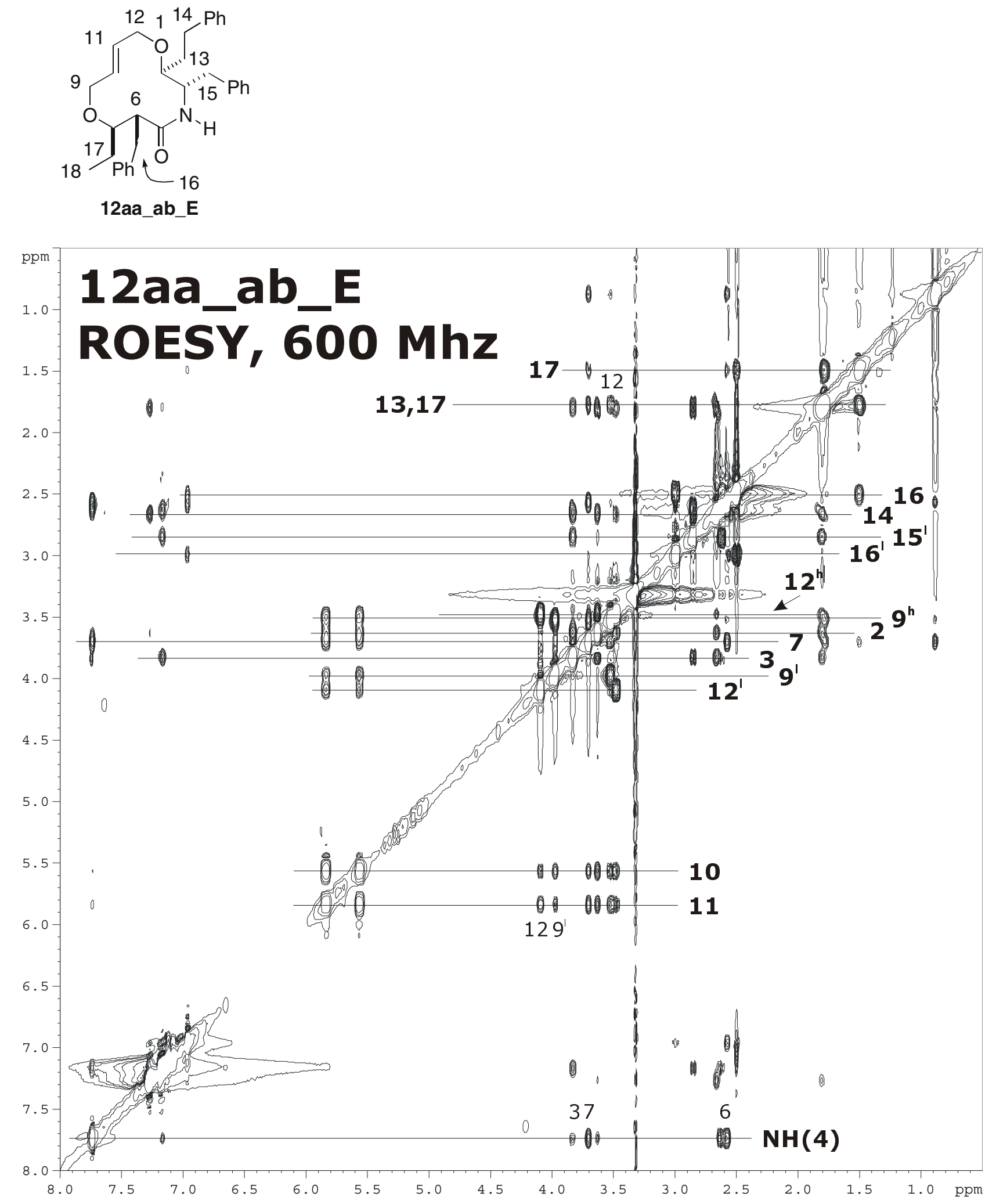
Signal assignment for the cis-Isomer 12aa_ab_Z (DMSO, $600 \mathrm{MHz}, 300 \mathrm{~K})$. Geminal methylene groups (cf. 16) are labeled as lowfield (cf. 16) and highfield signal $\left(16^{\mathrm{h}}\right)$, respectively. The corresponding carbon atom appears two times in the table and is enclosed in brackets. $\mathrm{m}=$ multiplett, no coupling can be extracted.

\begin{tabular}{|c|c|c|c|c|}
\hline & $\delta{ }^{1} \mathbf{H} \mathbf{~ p p m}$ & Integral & $\mathrm{J}$ & $\delta{ }^{13} \mathrm{C} \mathrm{ppm}$ \\
\hline 2 & 3.50 & 1 & $8.7 \mathrm{~Hz}, 3.5 \mathrm{~Hz}, 1.2 \mathrm{~Hz}$ & 78.06 \\
\hline 3 & 4.18 & 1 & $\mathrm{~m}$ & 52.58 \\
\hline 5 & - & - & - & 172.04 \\
\hline 6 & 3.02 & 1 & $10.8 \mathrm{~Hz}, 3.3 \mathrm{~Hz}$ & 48.79 \\
\hline 7 & 3.44 & 1 & $10.7 \mathrm{~Hz}, 2.6 \mathrm{~Hz}$ & 80.35 \\
\hline $9^{1}$ & 4.30 & 1 & $\mathrm{~m}$ & 63.32 \\
\hline $9^{\text {h }}$ & 4.08 & 1 & $11.0 \mathrm{~Hz}, 6.4 \mathrm{~Hz}$ & $(63.32)$ \\
\hline 10 & 5.68 & 1 & $\mathrm{~m}$ & 129.39 \\
\hline 11 & 5.73 & 1 & $\mathrm{~m}$ & 130.61 \\
\hline $12^{1}$ & 4.30 & 1 & $\mathrm{~m}$ & 63.12 \\
\hline $12^{\mathrm{h}}$ & 3.86 & 1 & $11.1 \mathrm{~Hz}, 5.8 \mathrm{~Hz}$ & $(63.12)$ \\
\hline 13 & $1.68,1.78$ & 2 & $\mathrm{~m}$ & 33.95 \\
\hline 14 & $2.51,2.70$ & 2 & $\mathrm{~m}$ & 32.03 \\
\hline 15 & $2.55,2.70$ & 2 & $\mathrm{~m}$ & 33.64 \\
\hline $16^{1}$ & 2.88 & 1 & $13.8 \mathrm{~Hz}, 10.5 \mathrm{~Hz}$ & 32.14 \\
\hline $16^{h}$ & 2.42 & 1 & $14.0 \mathrm{~Hz}, 3.2 \mathrm{~Hz}$ & $(32.14)$ \\
\hline 17 & $1.52,1.68$ & 2 & $\mathrm{~m}$ & 23.85 \\
\hline 18 & 0.88 & 3 & $7.3 \mathrm{~Hz}$ & 11.10 \\
\hline
\end{tabular}

Ar-C: $125.2-142.03$ ppm, 12 signals

Ar-H: $6.95-7.30$ ppm, multiplett

N-H: 7.72 ppm, $J=7.2 \mathrm{~Hz}$ 

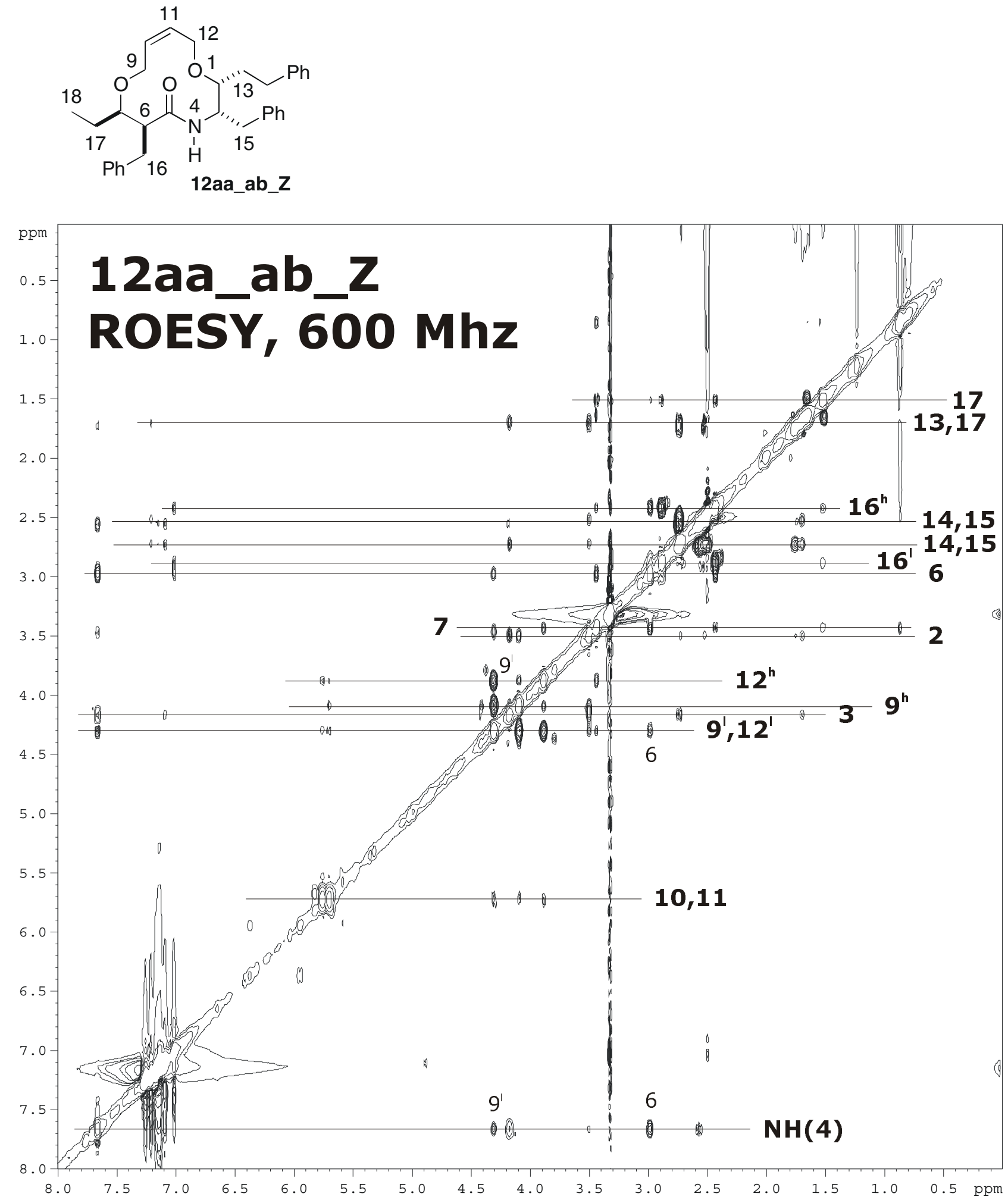

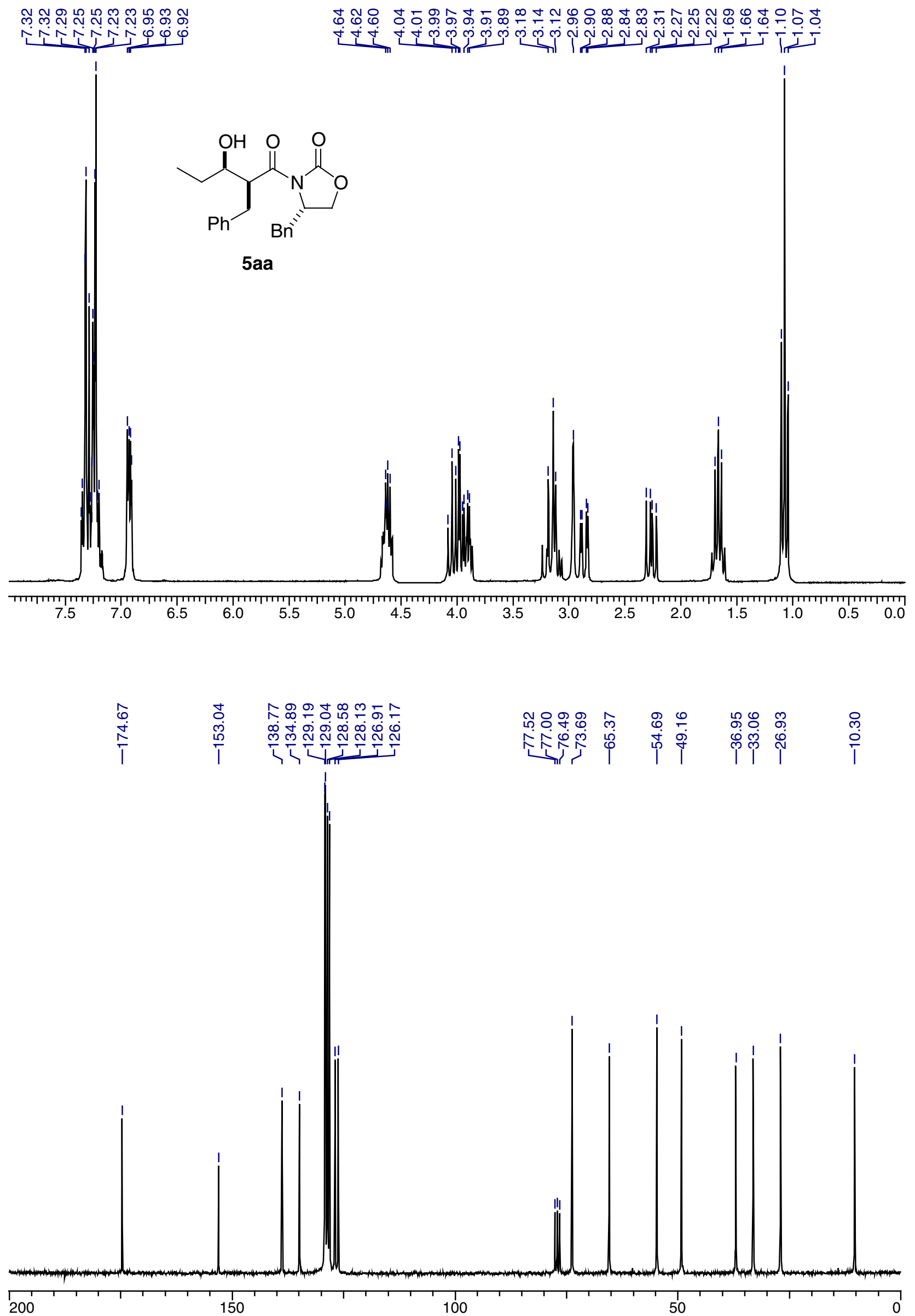


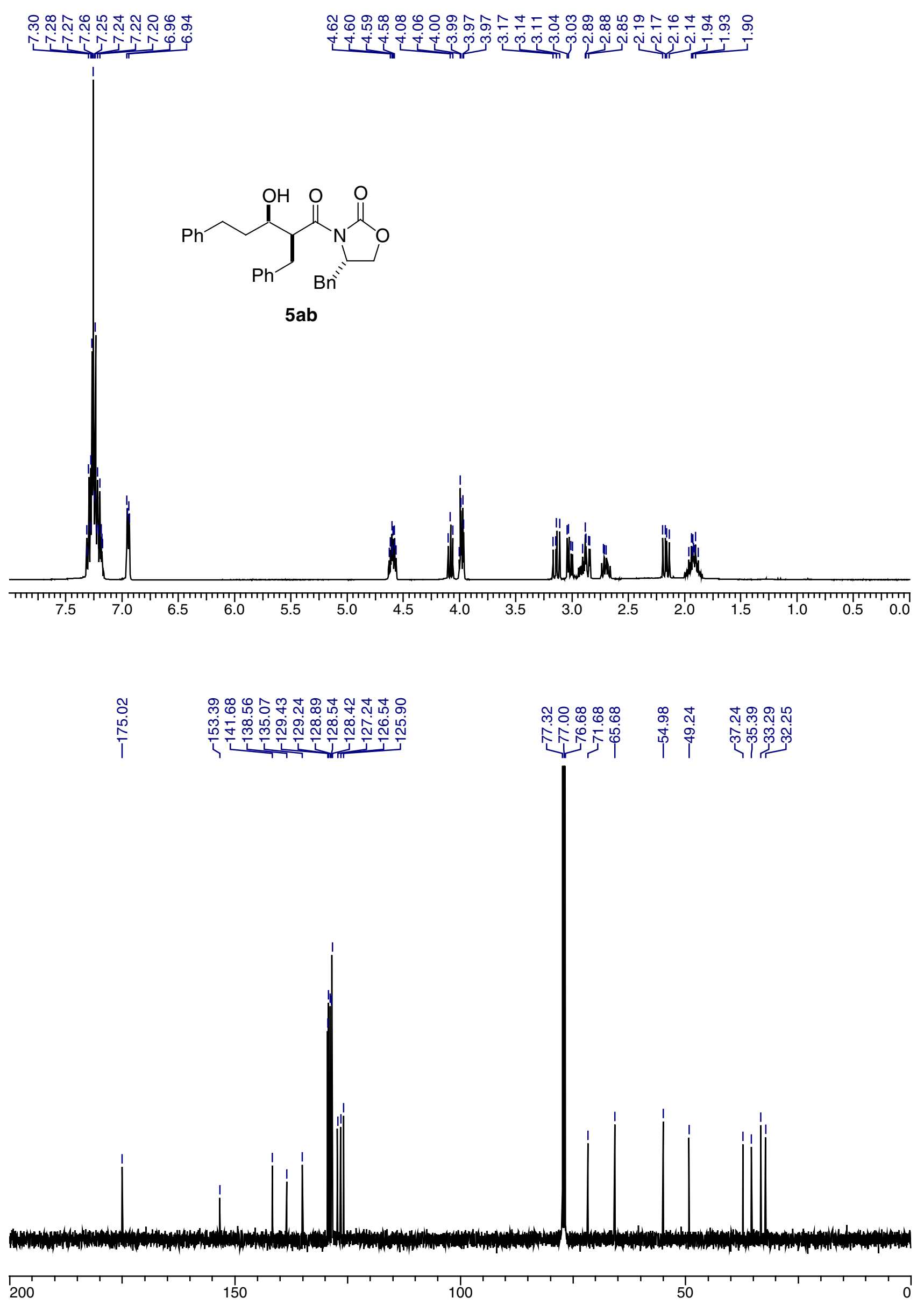



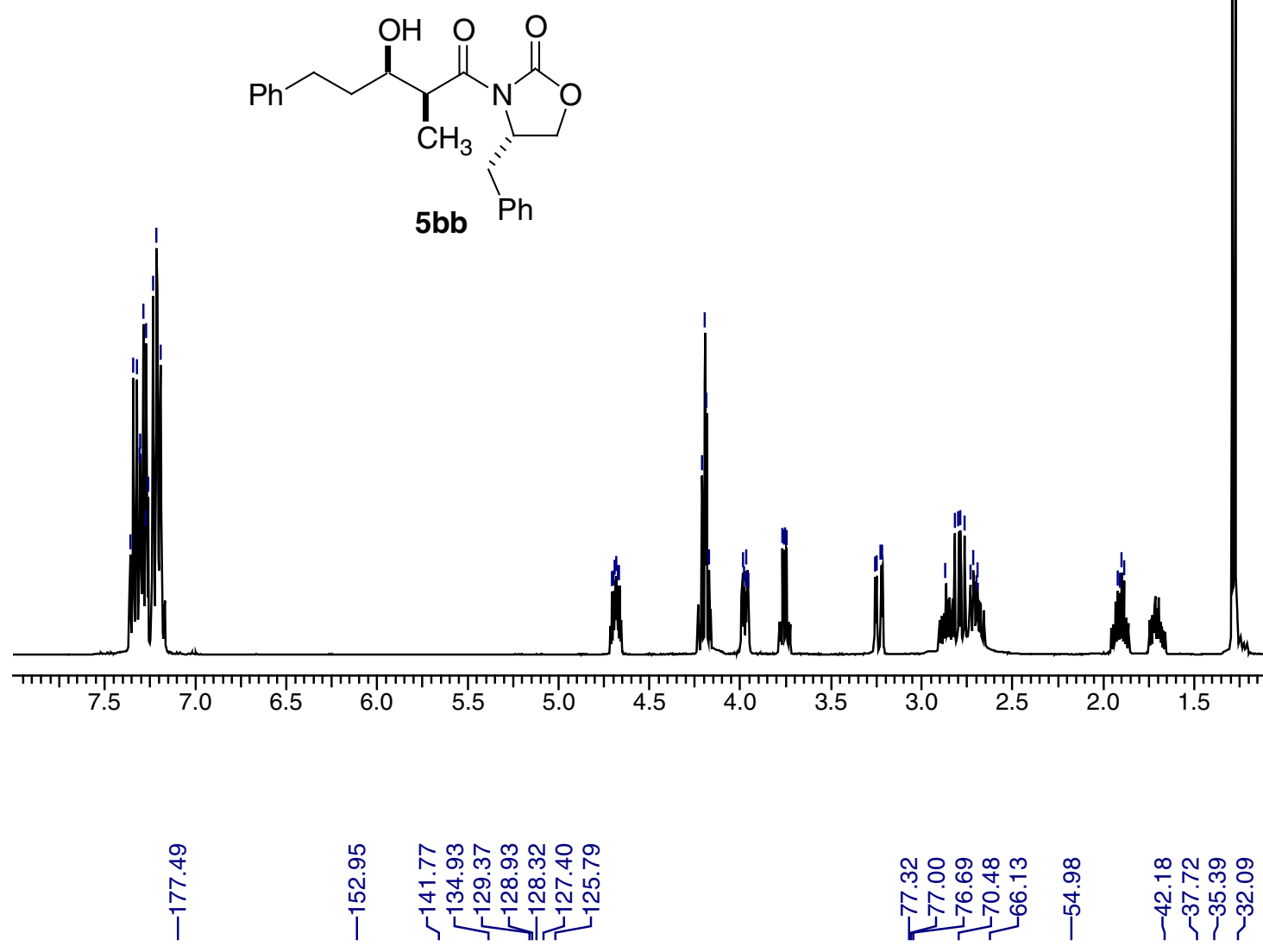

ํㅜㅁ

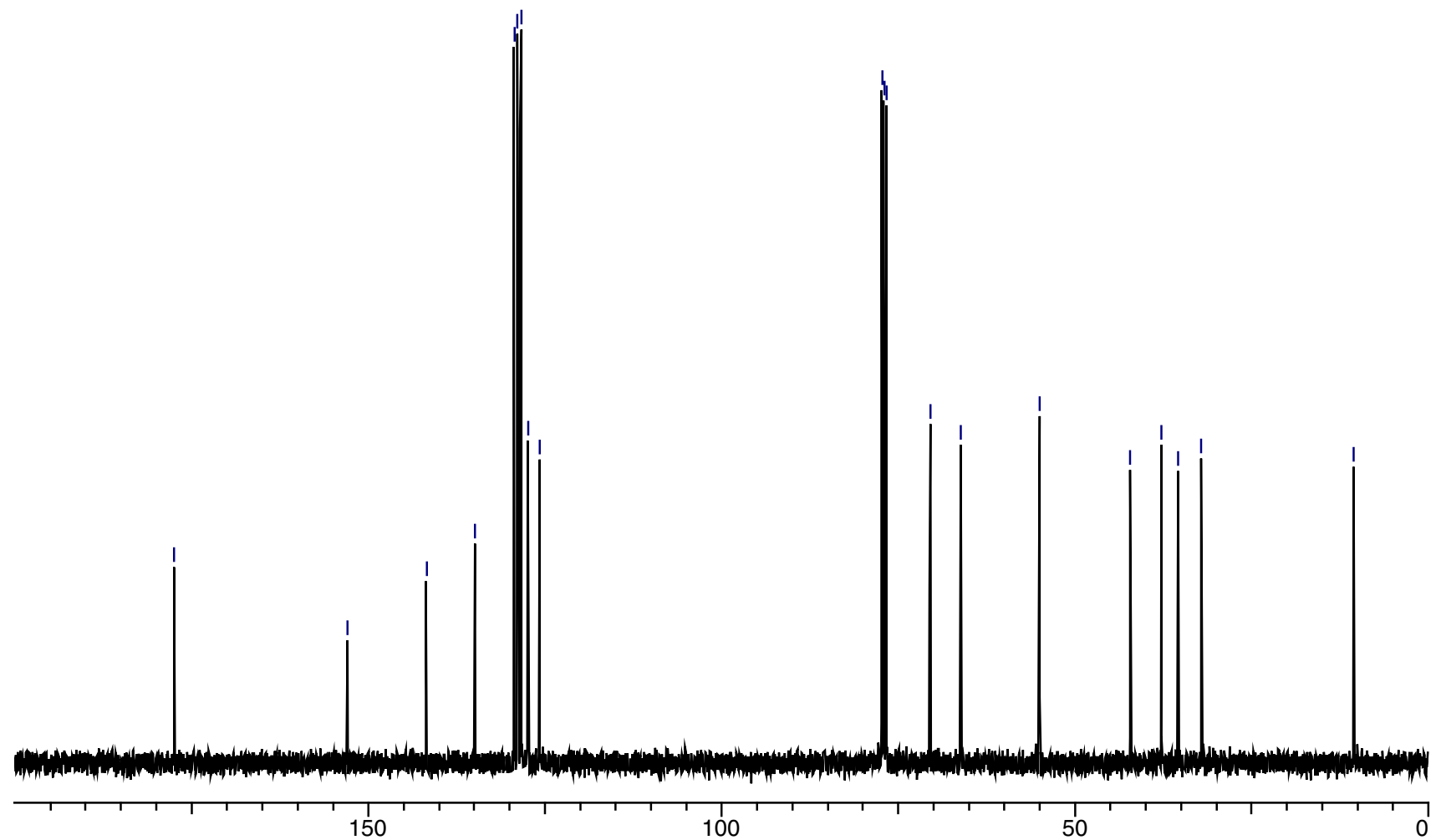



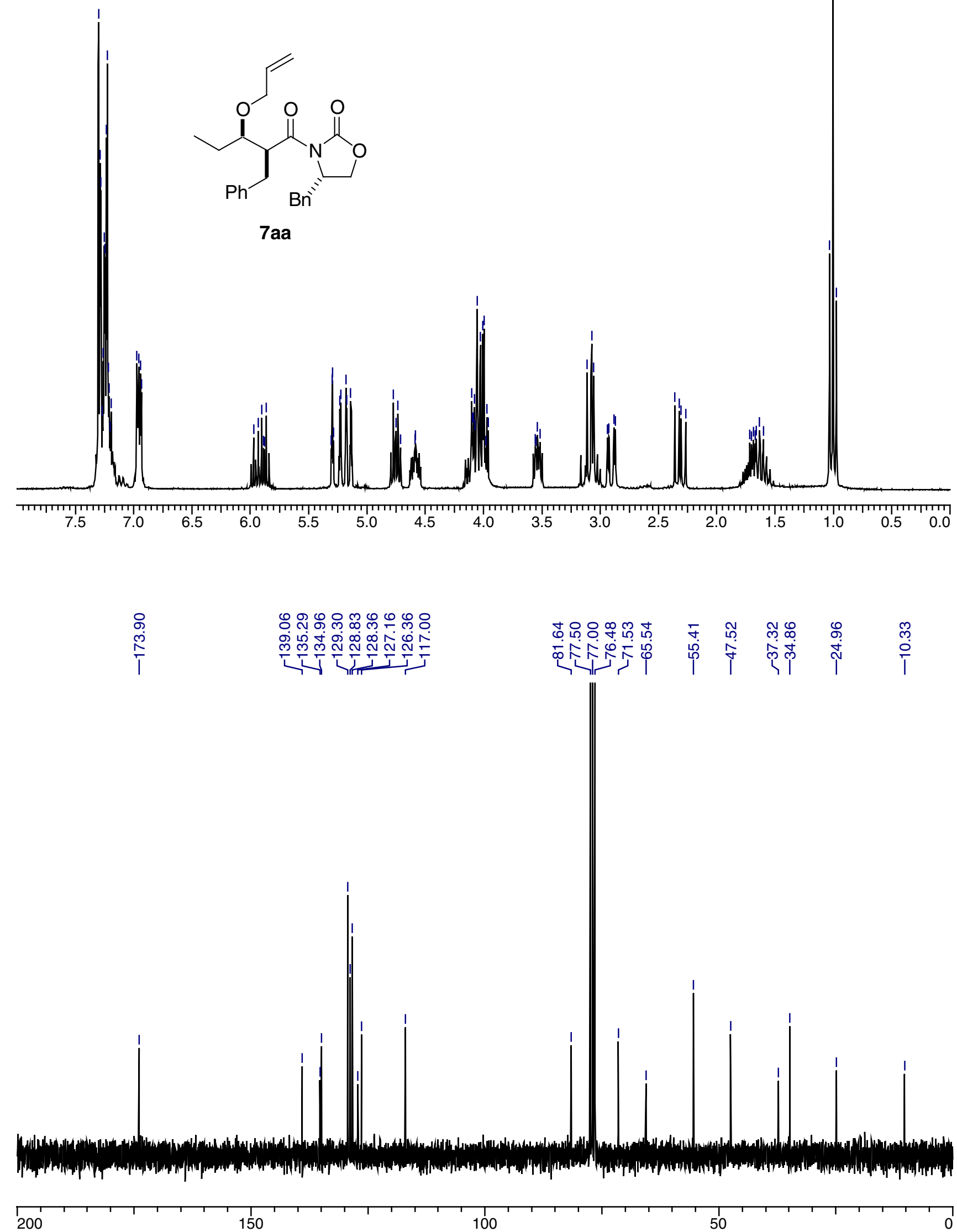


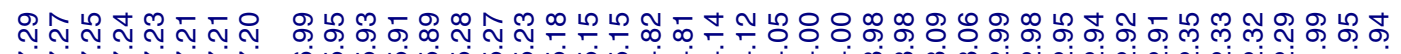
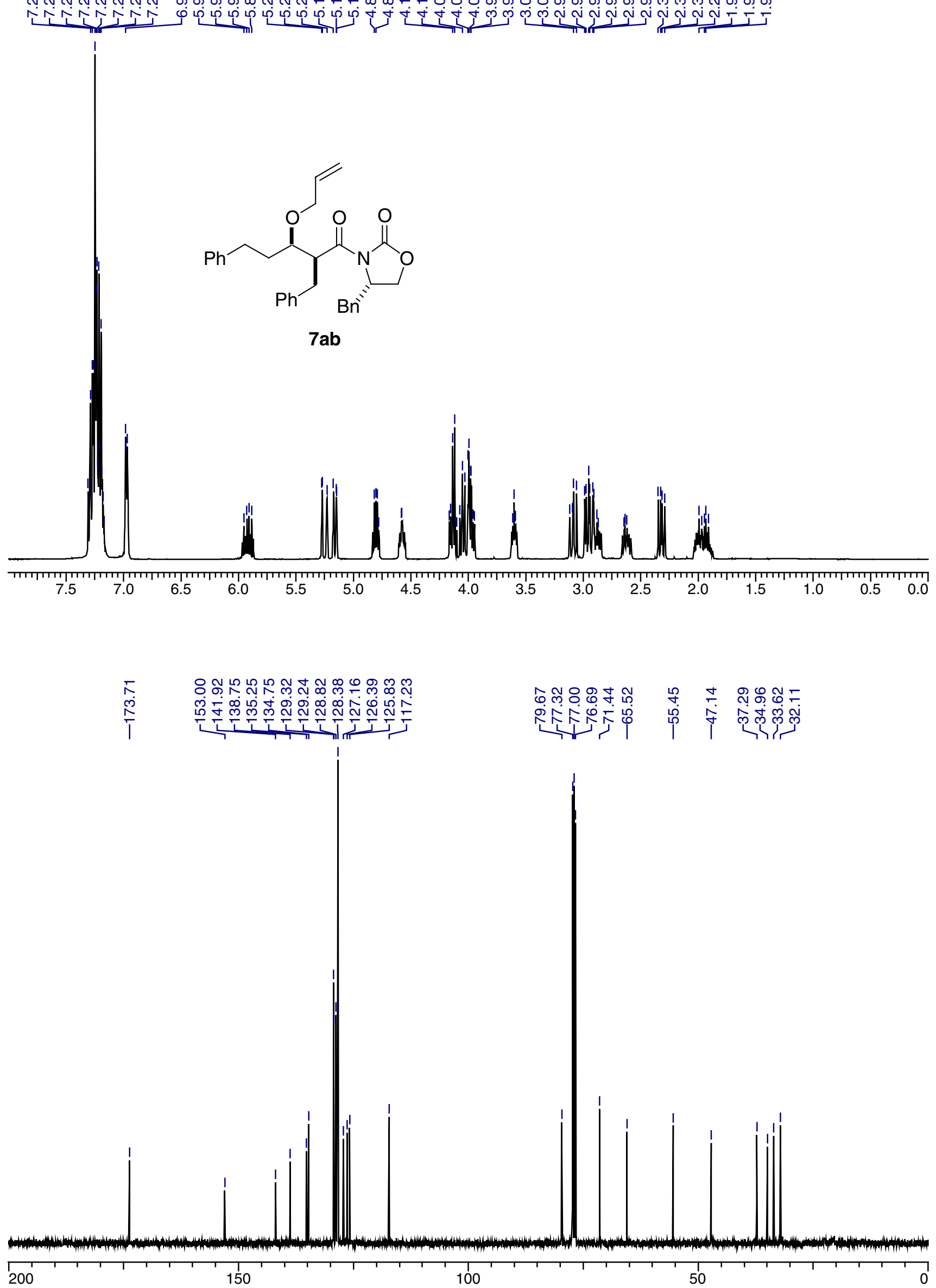

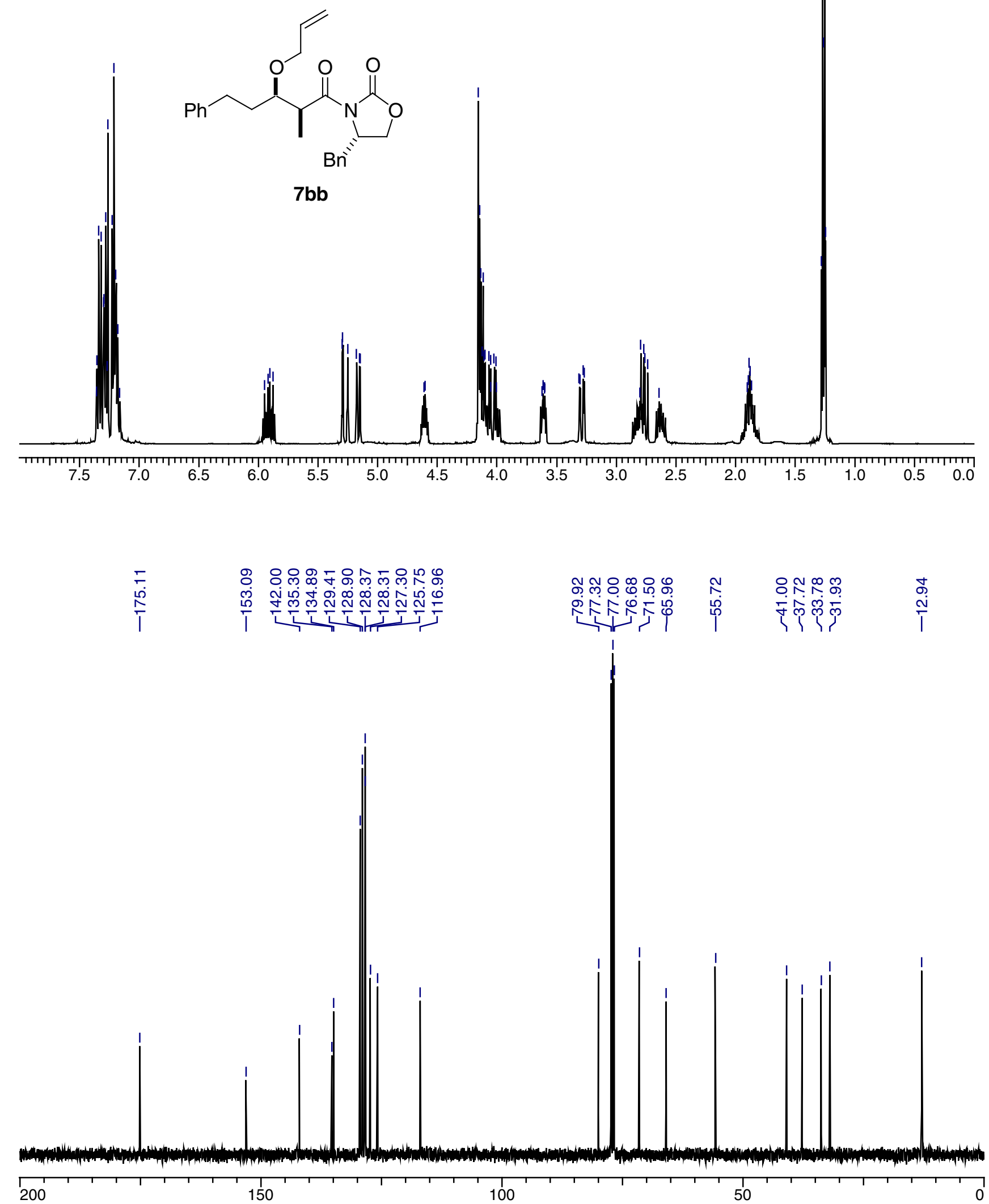

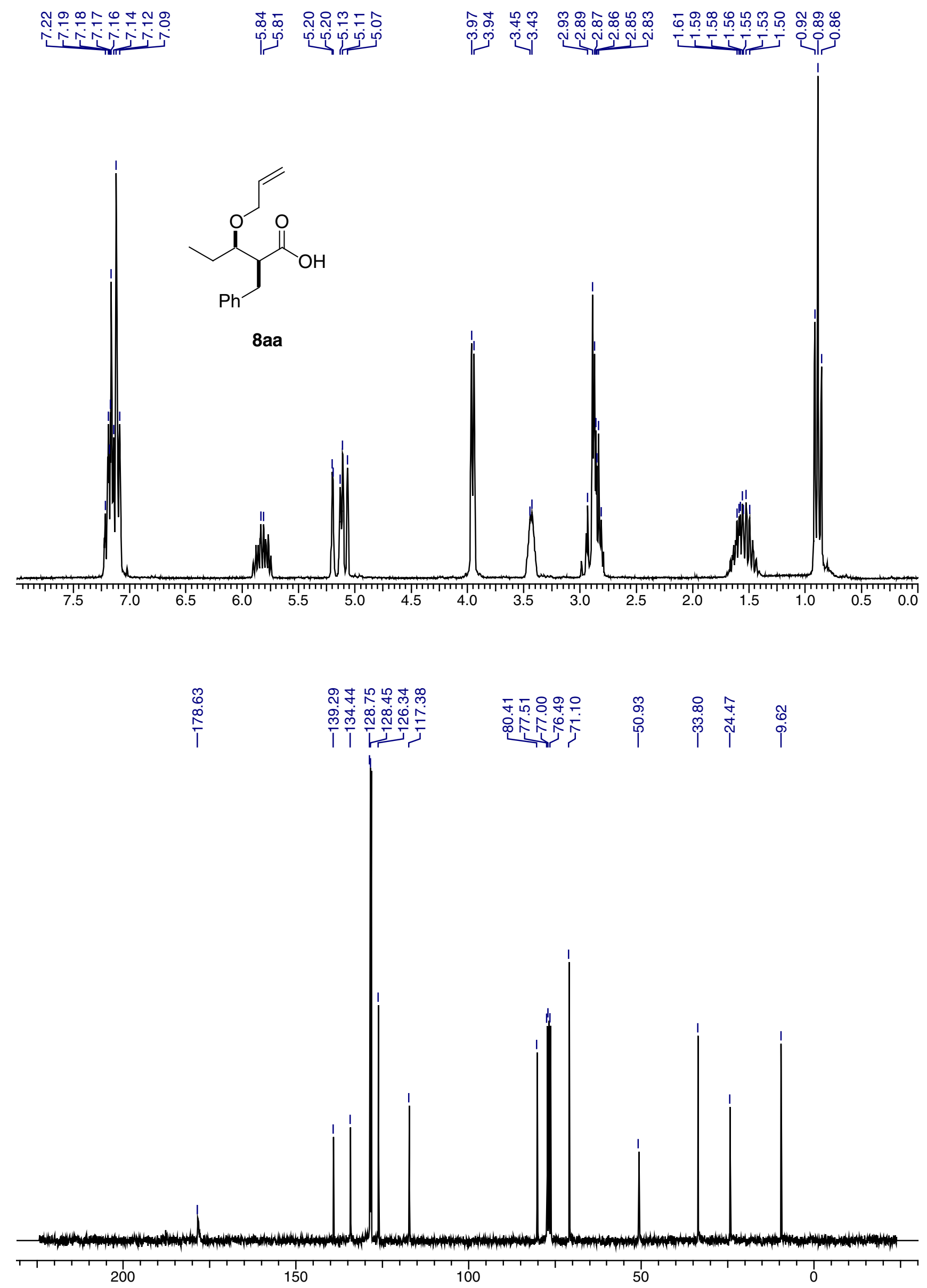

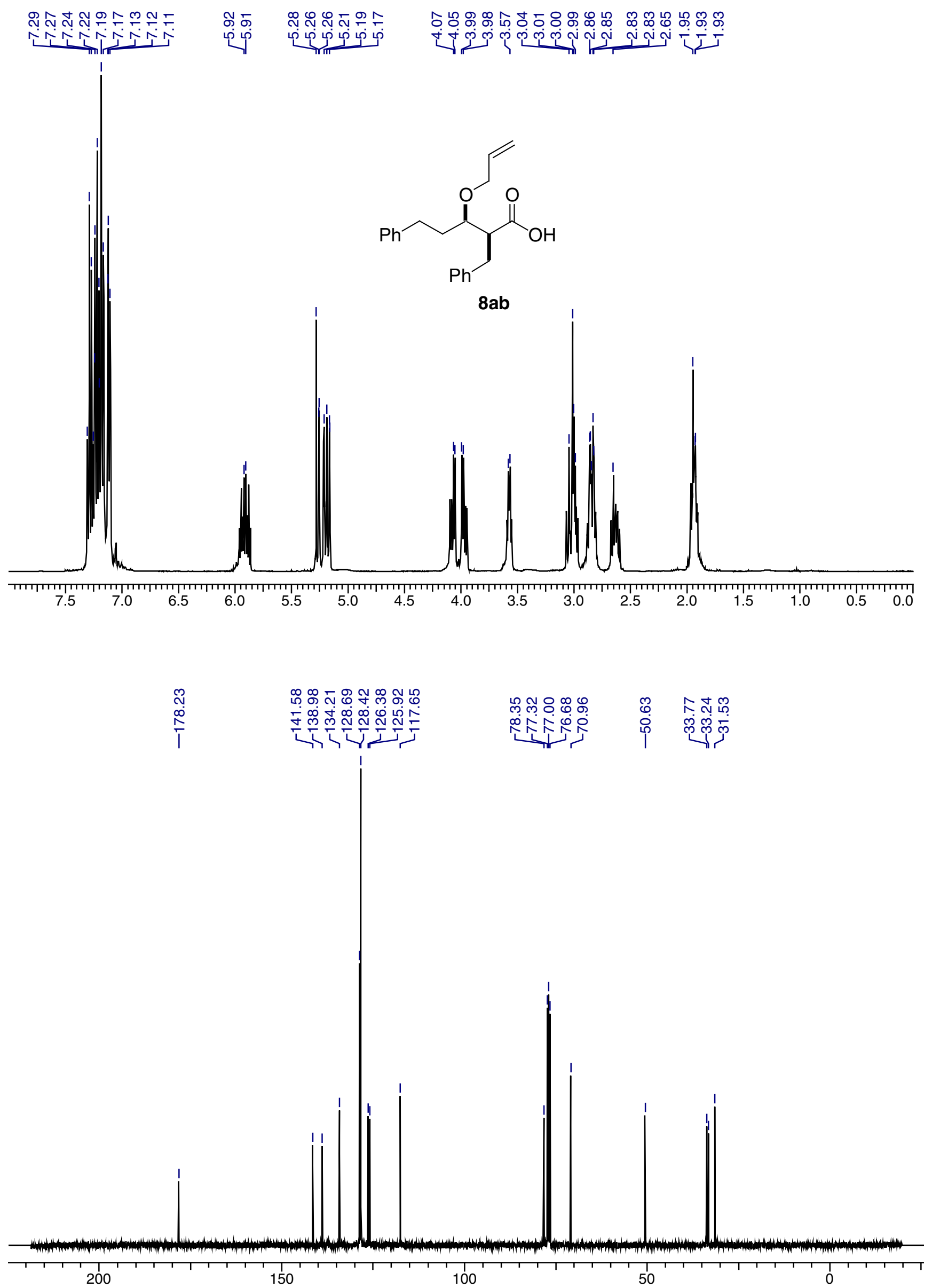

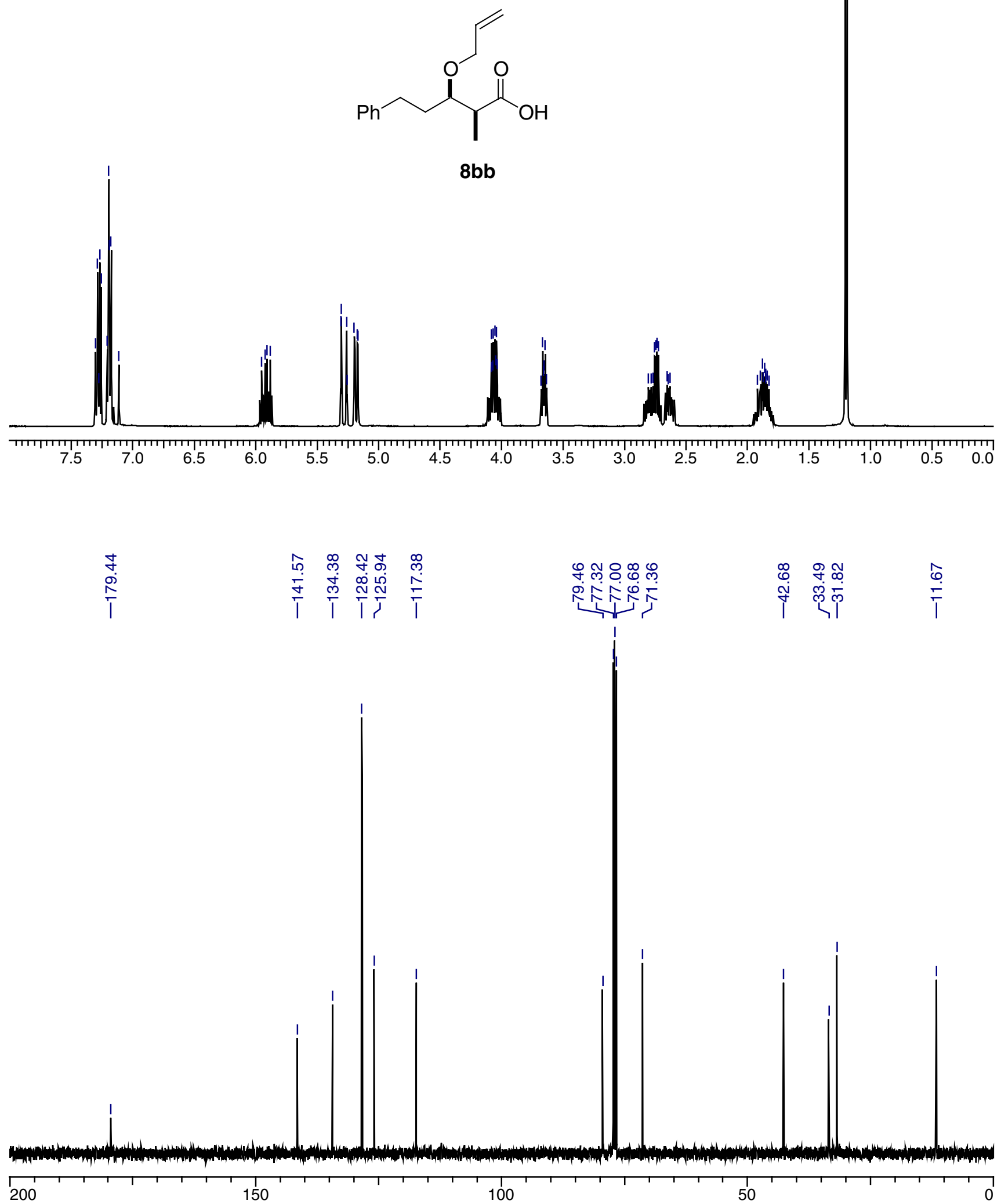
<smiles>C=CCOC(CC)C(N)Cc1ccccc1</smiles>

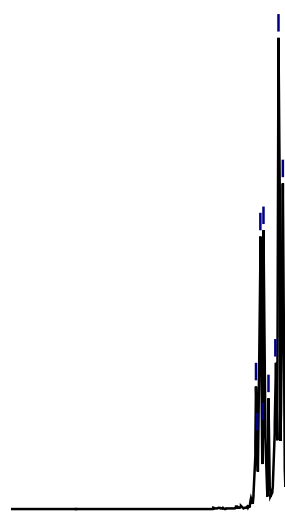

9aa
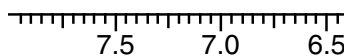

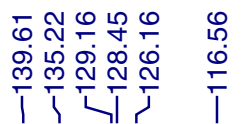

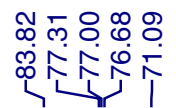

$\begin{array}{ll}\stackrel{\infty}{N} & \infty \\ \stackrel{\infty}{+} & \infty \\ \stackrel{p}{p} & \stackrel{p}{i}\end{array}$

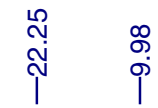

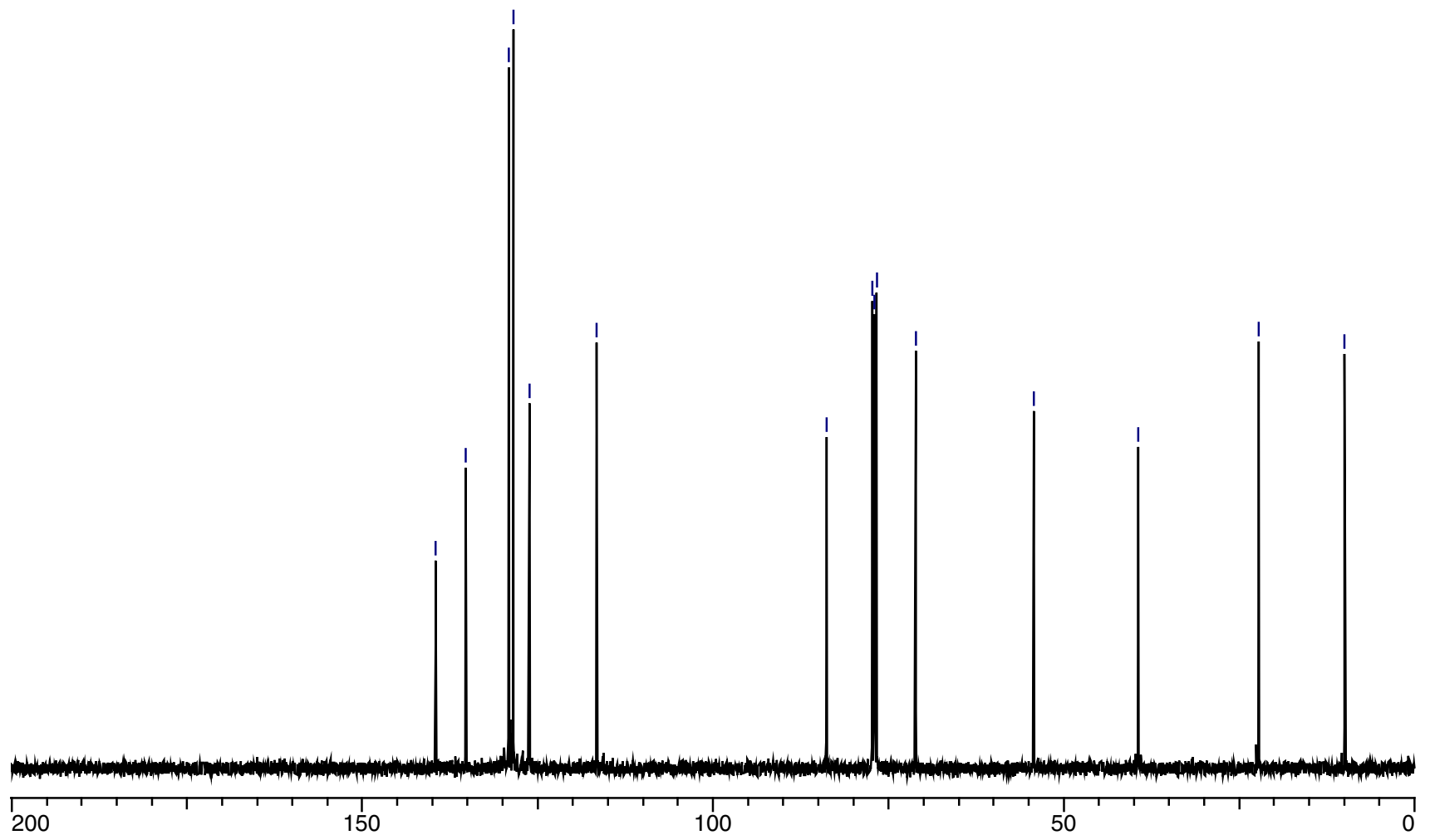



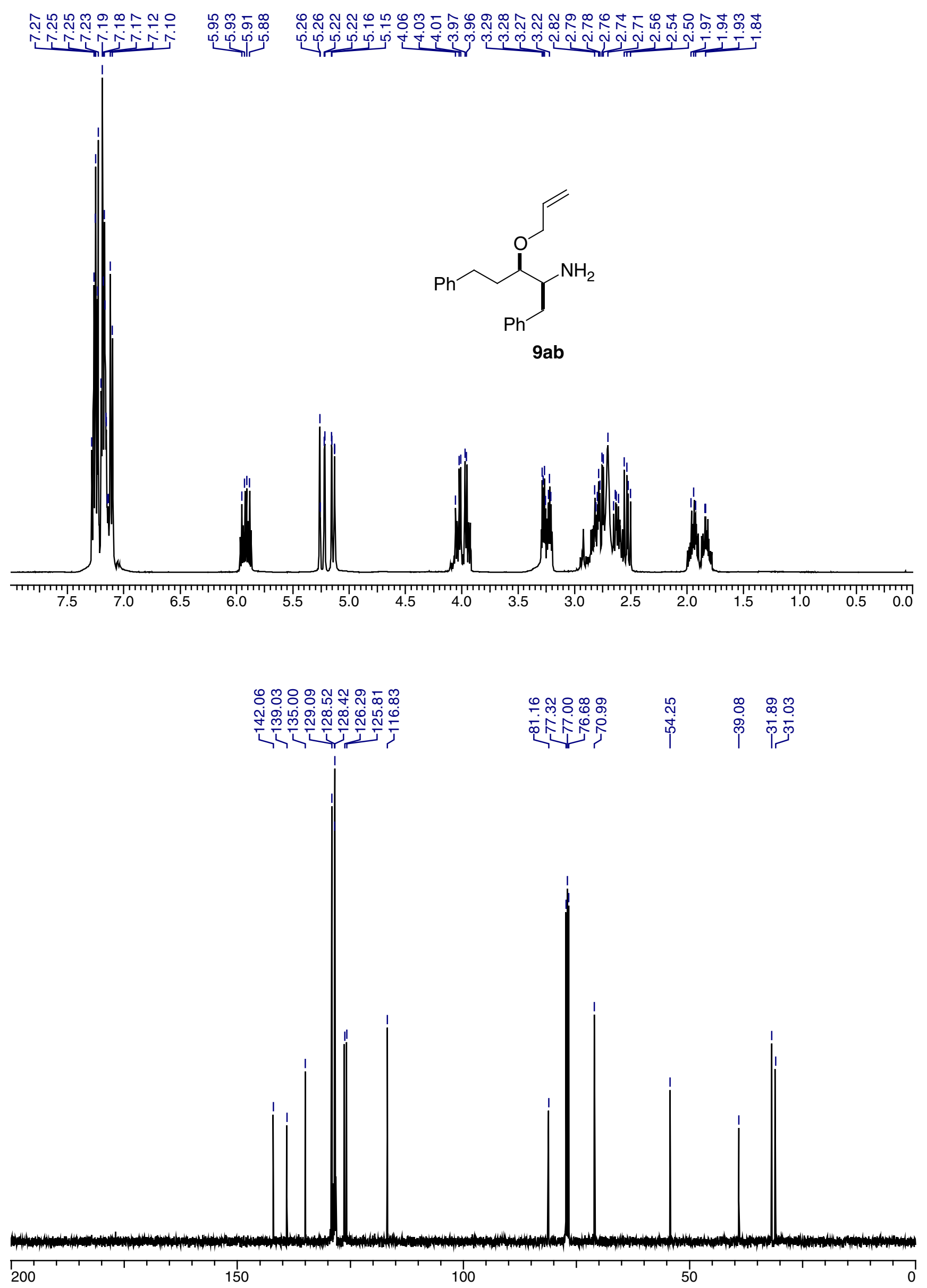

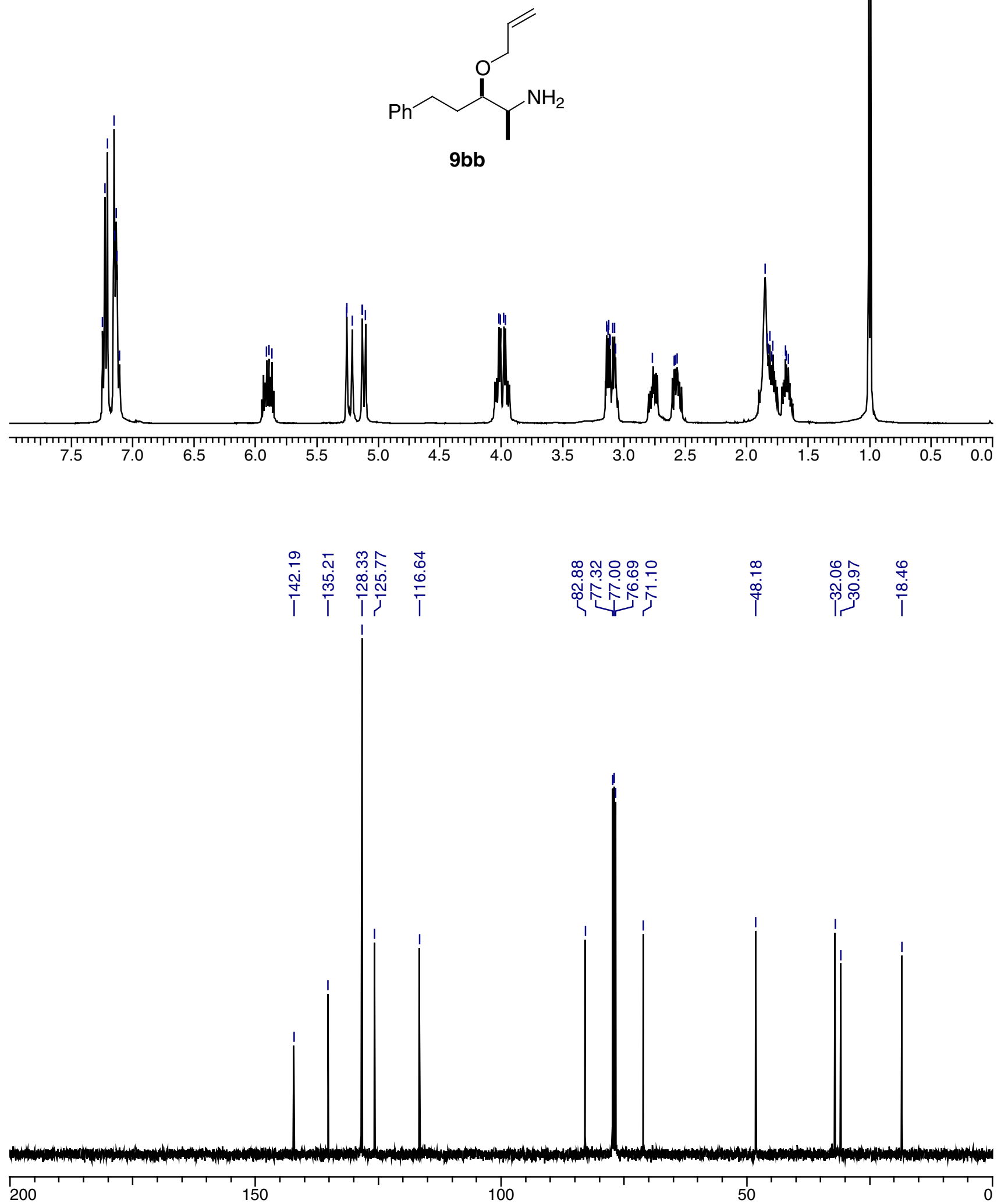

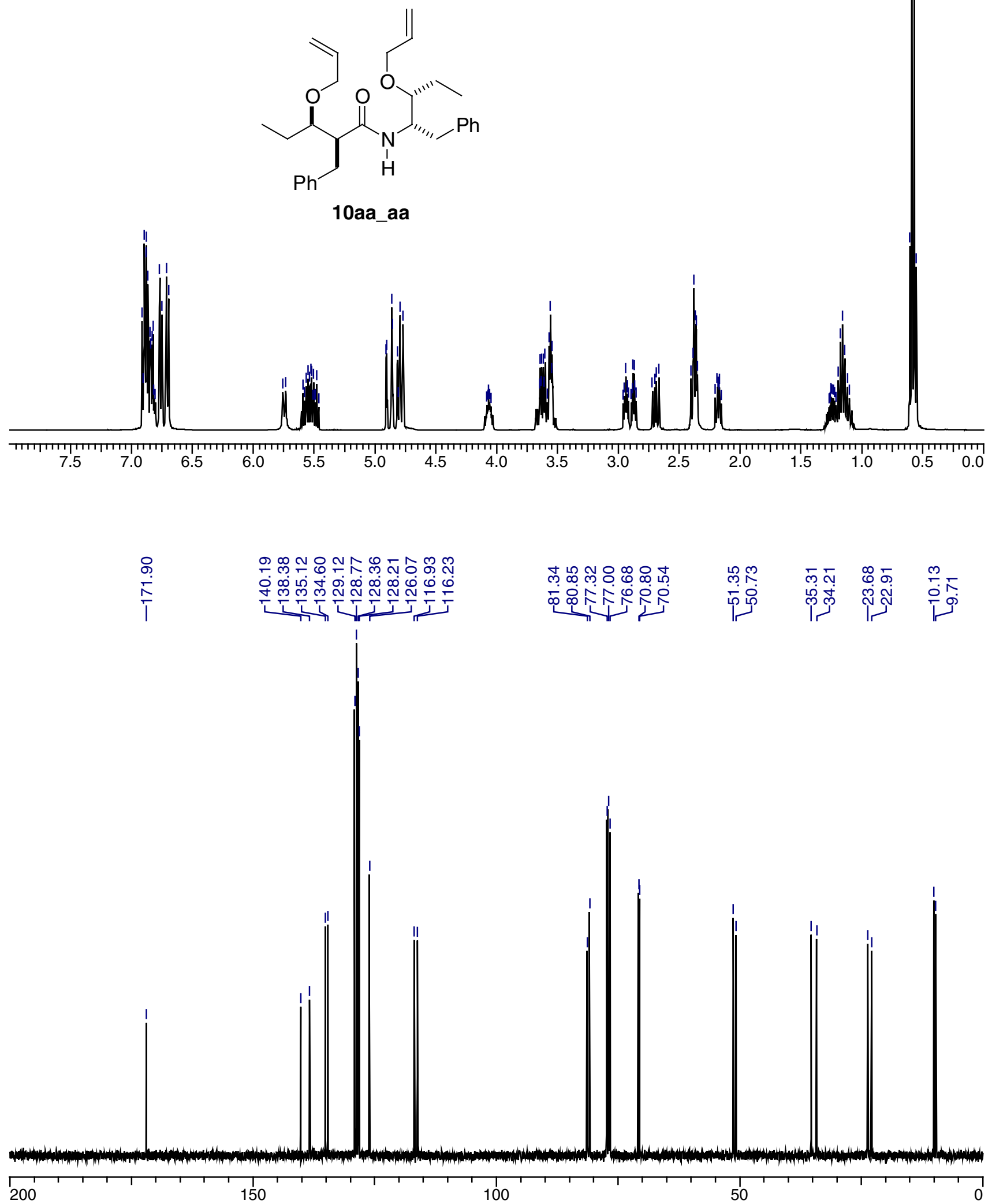


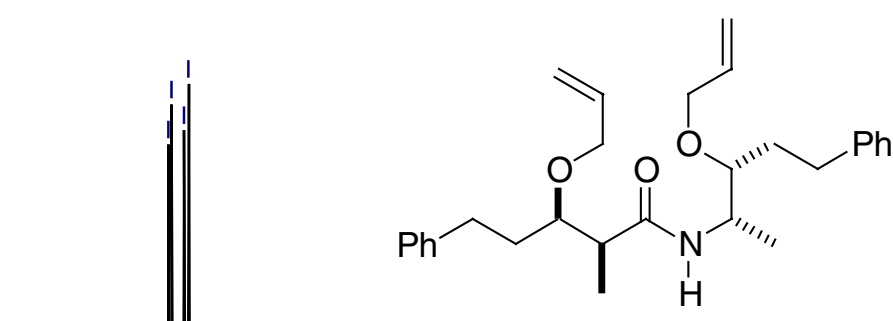

10bb_bb

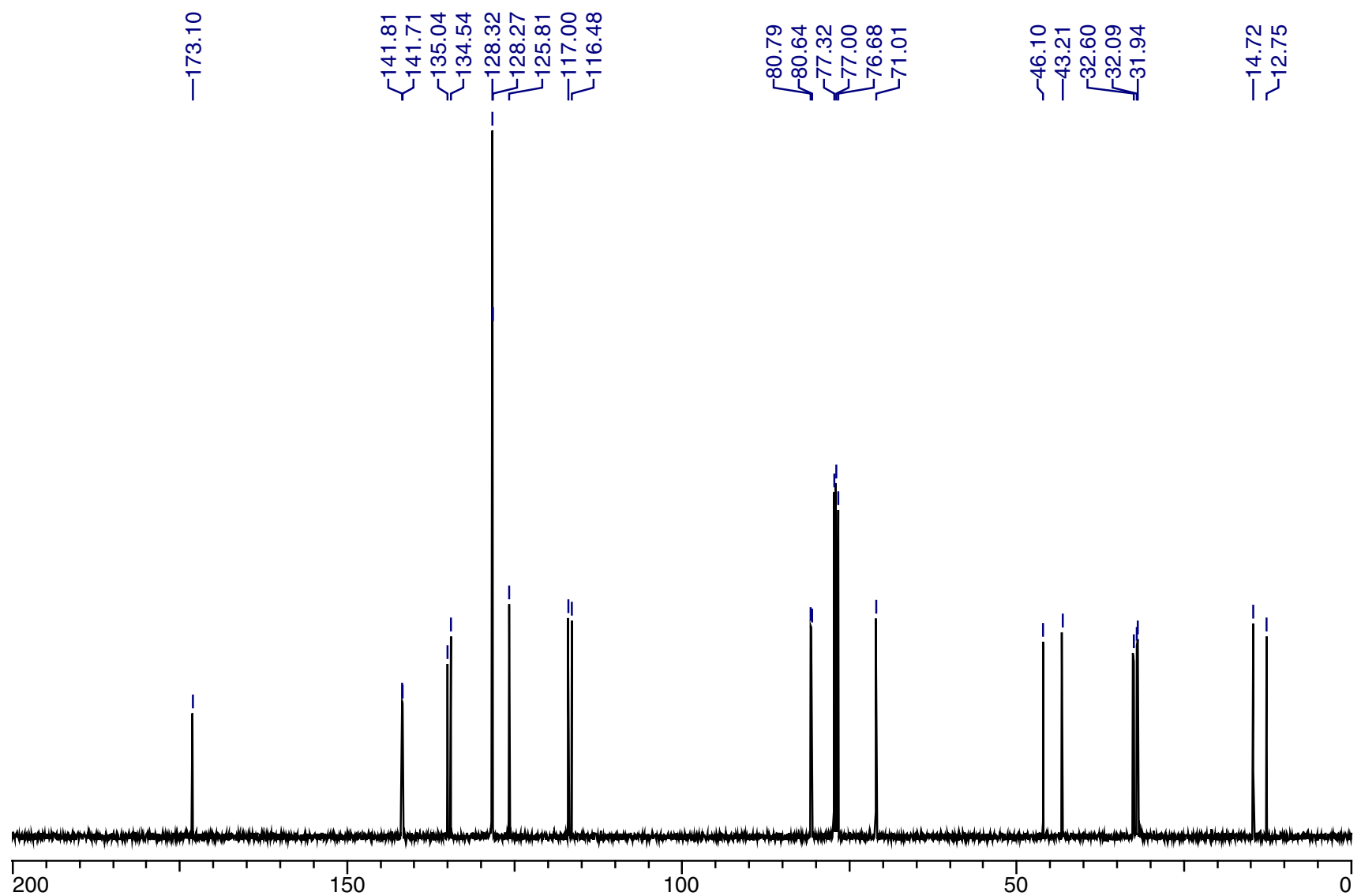




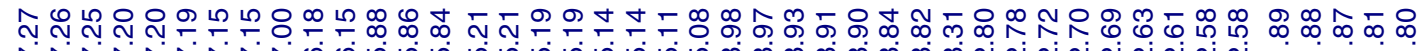

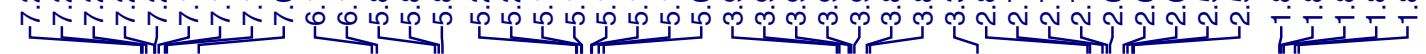
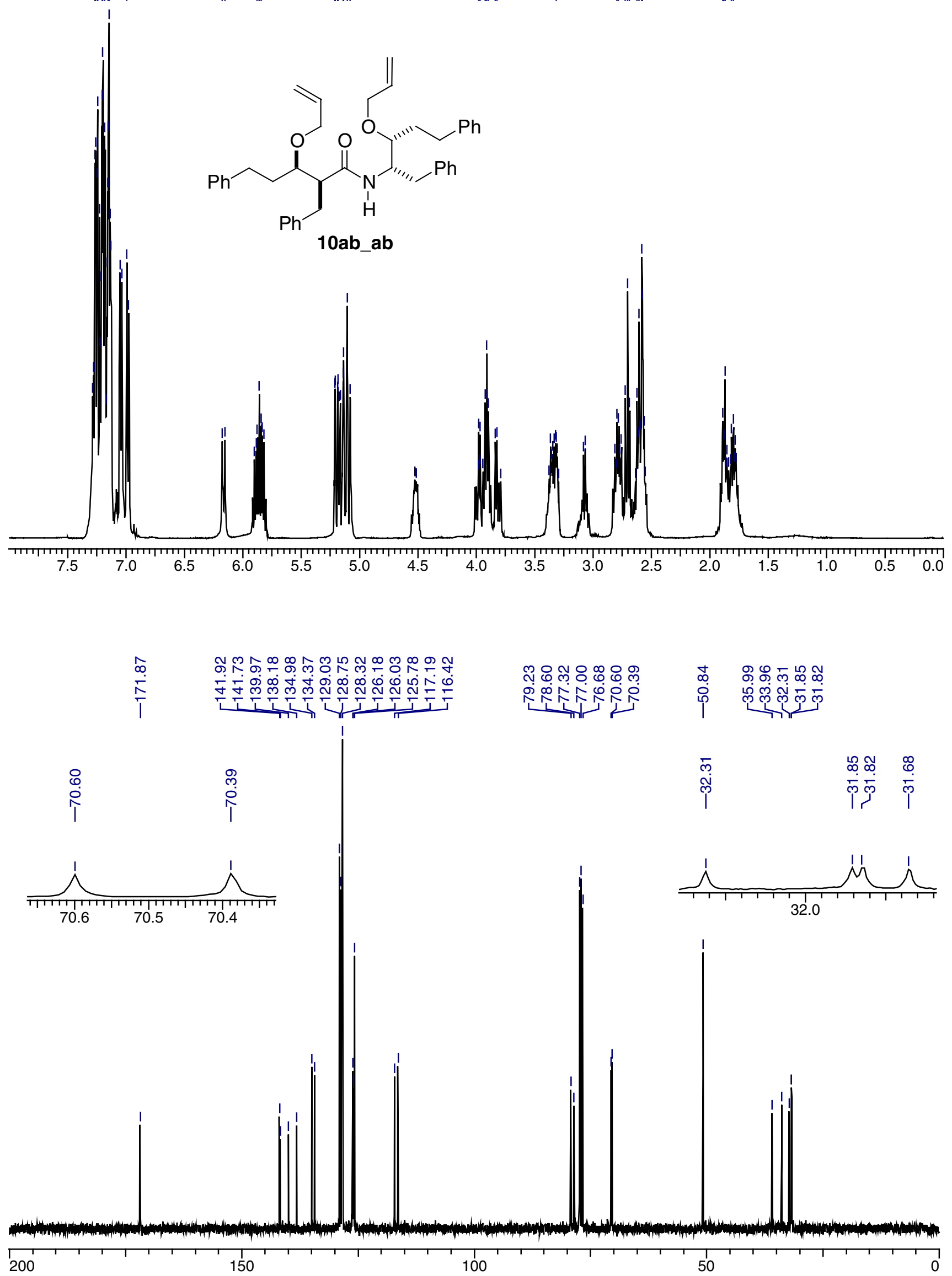

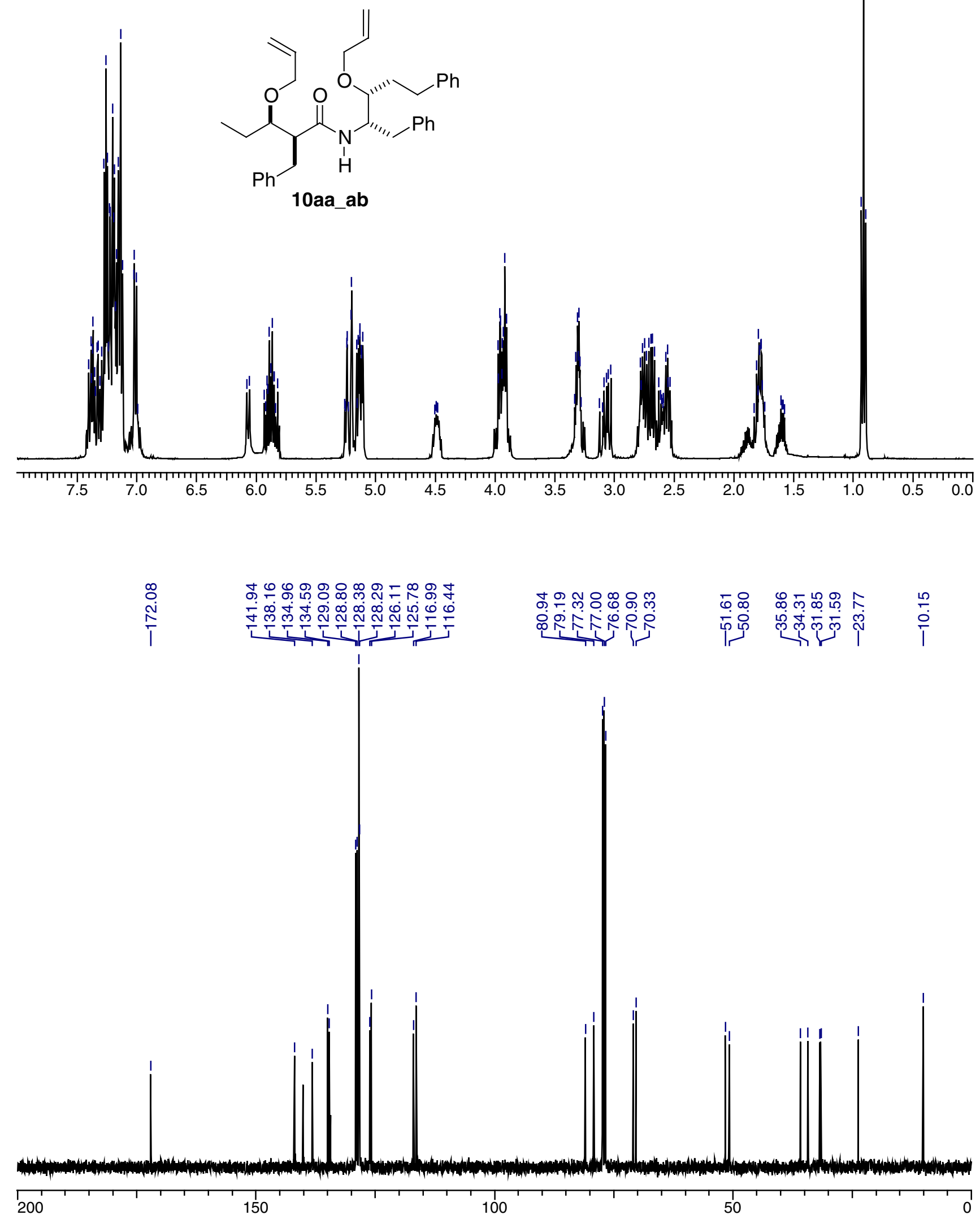


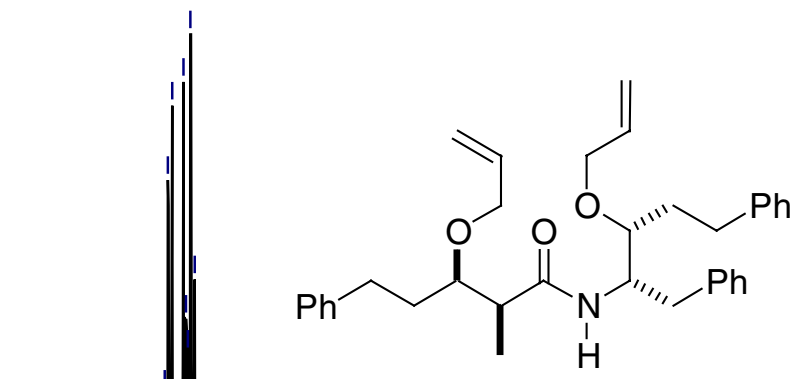

10bb_ab
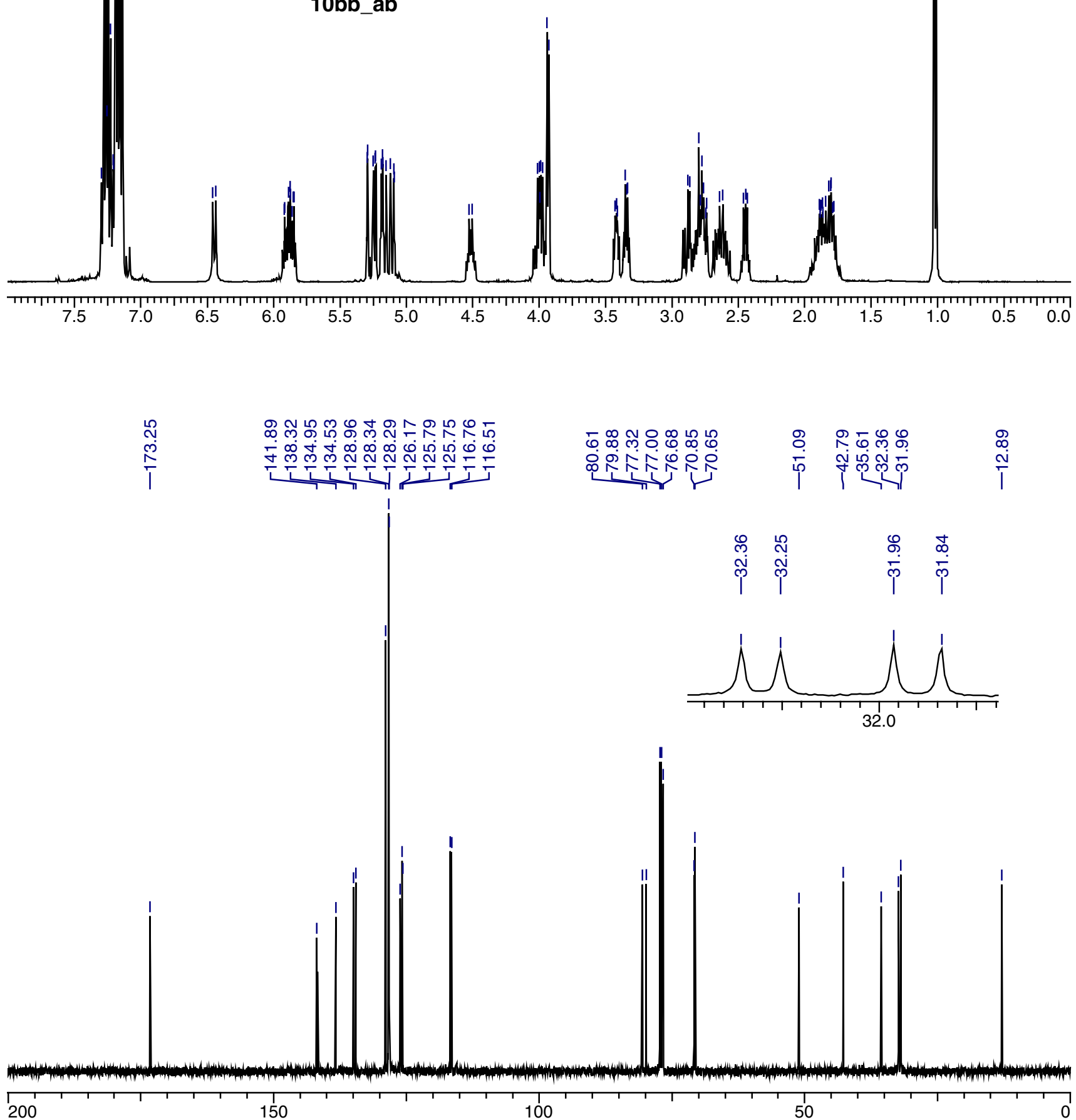

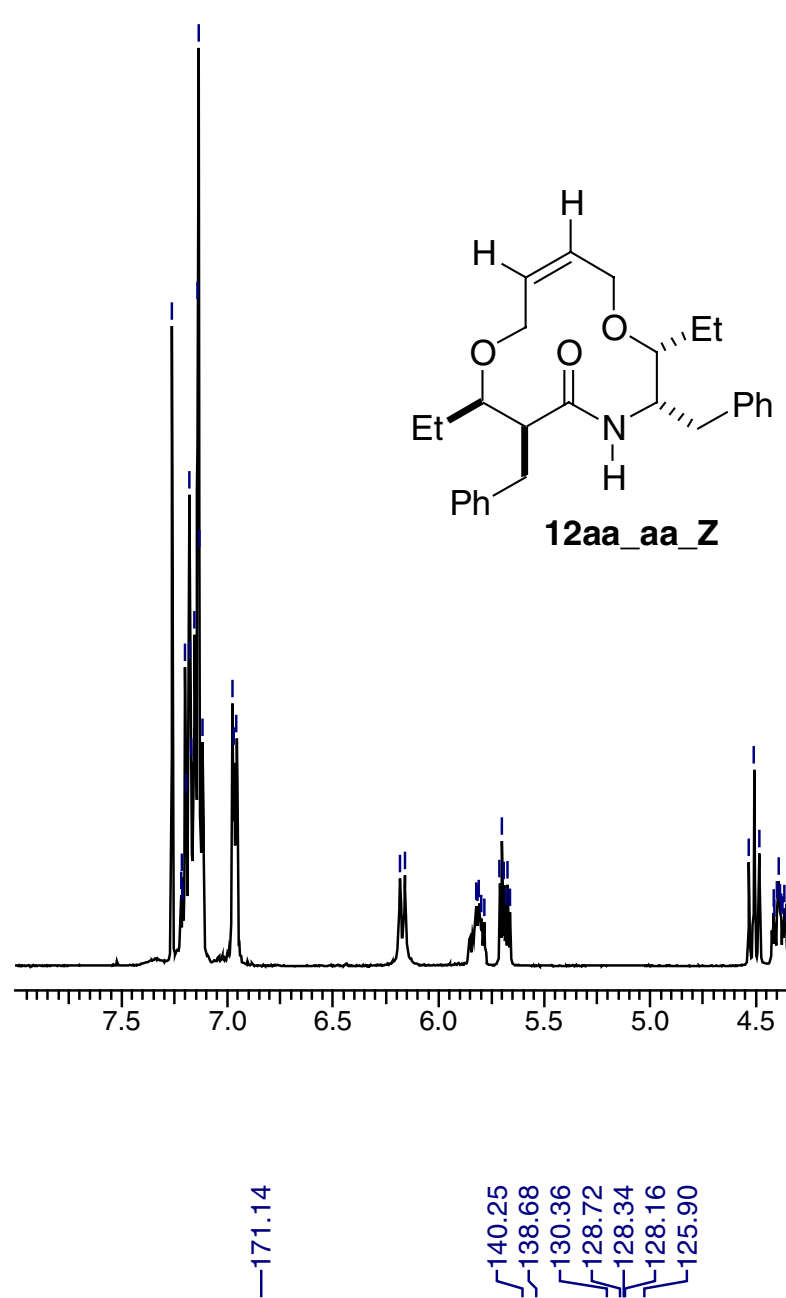

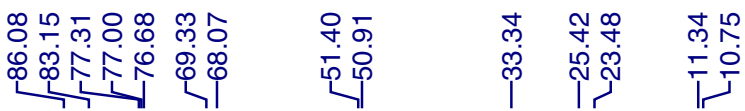

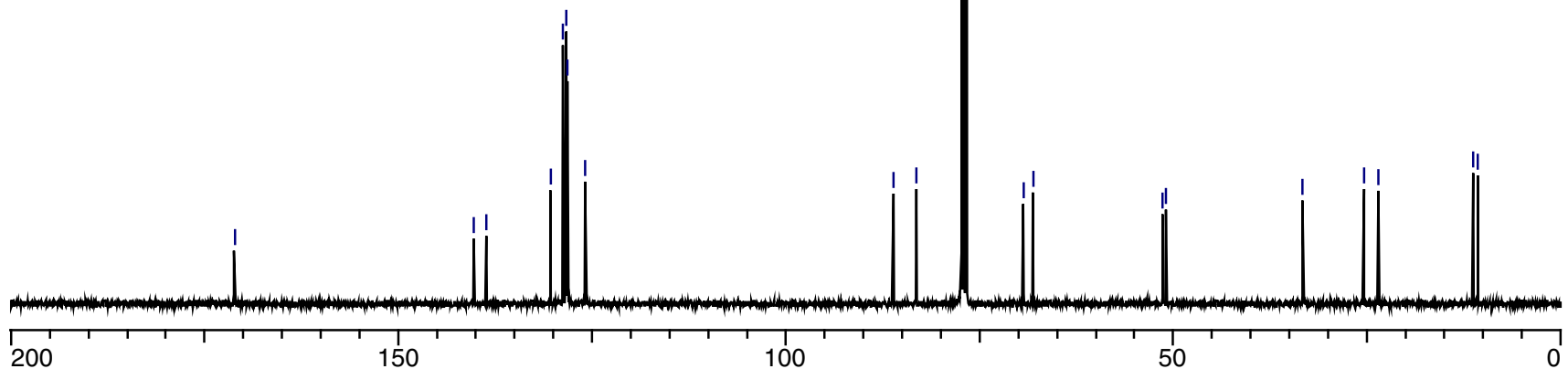




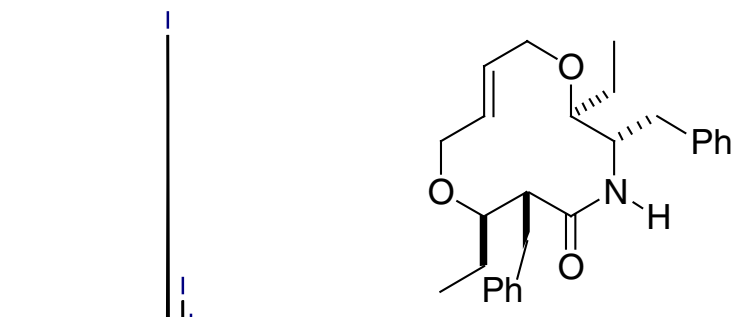

12aa_aa_E
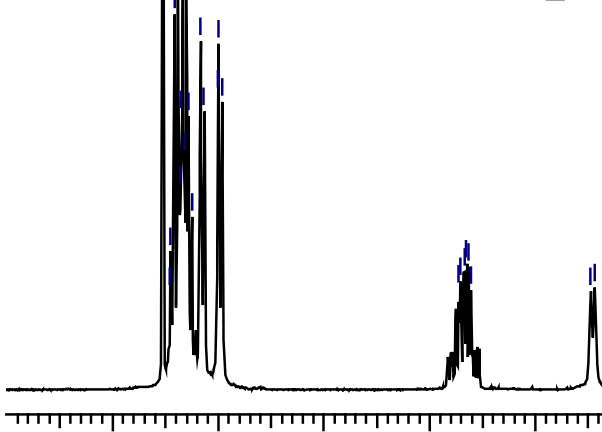

7.5
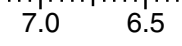

6.0

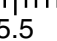

5.0

4.5

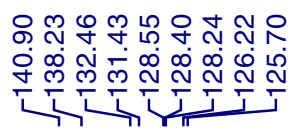

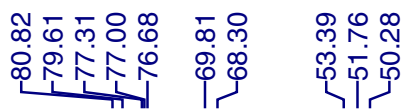

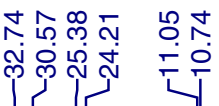
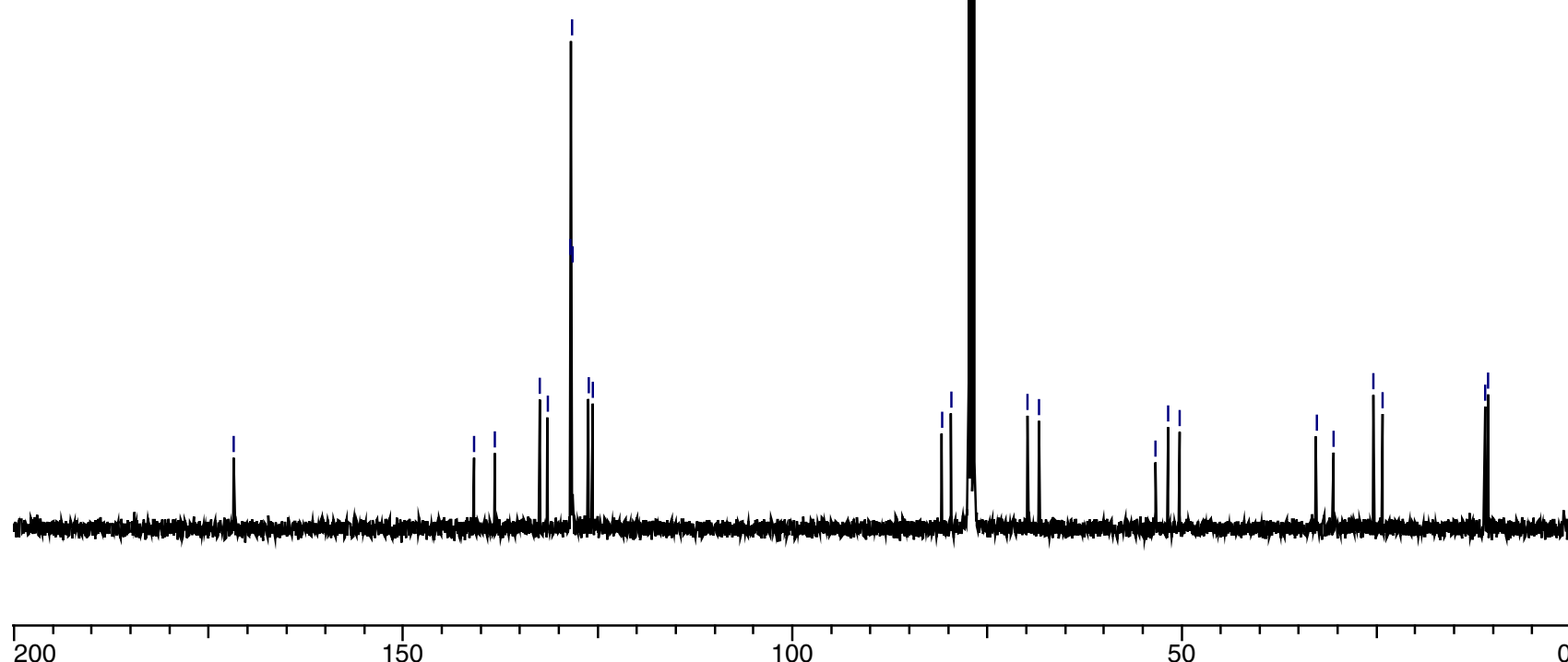

50 


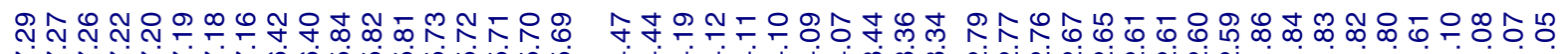

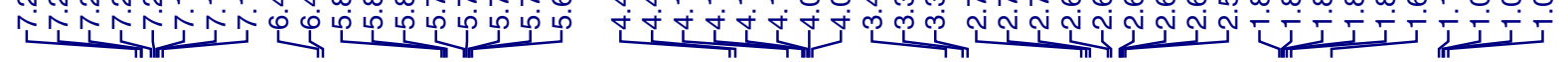
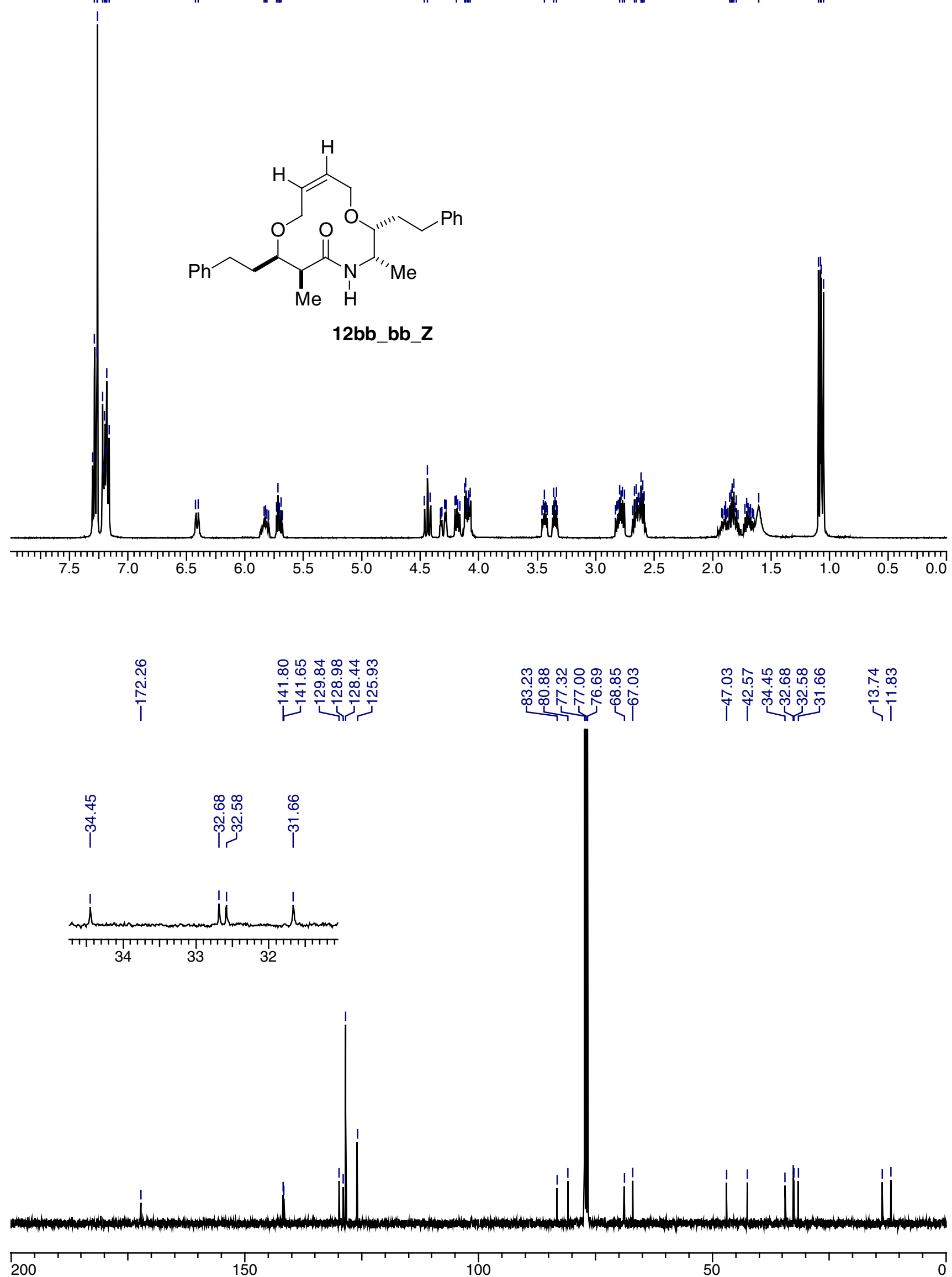

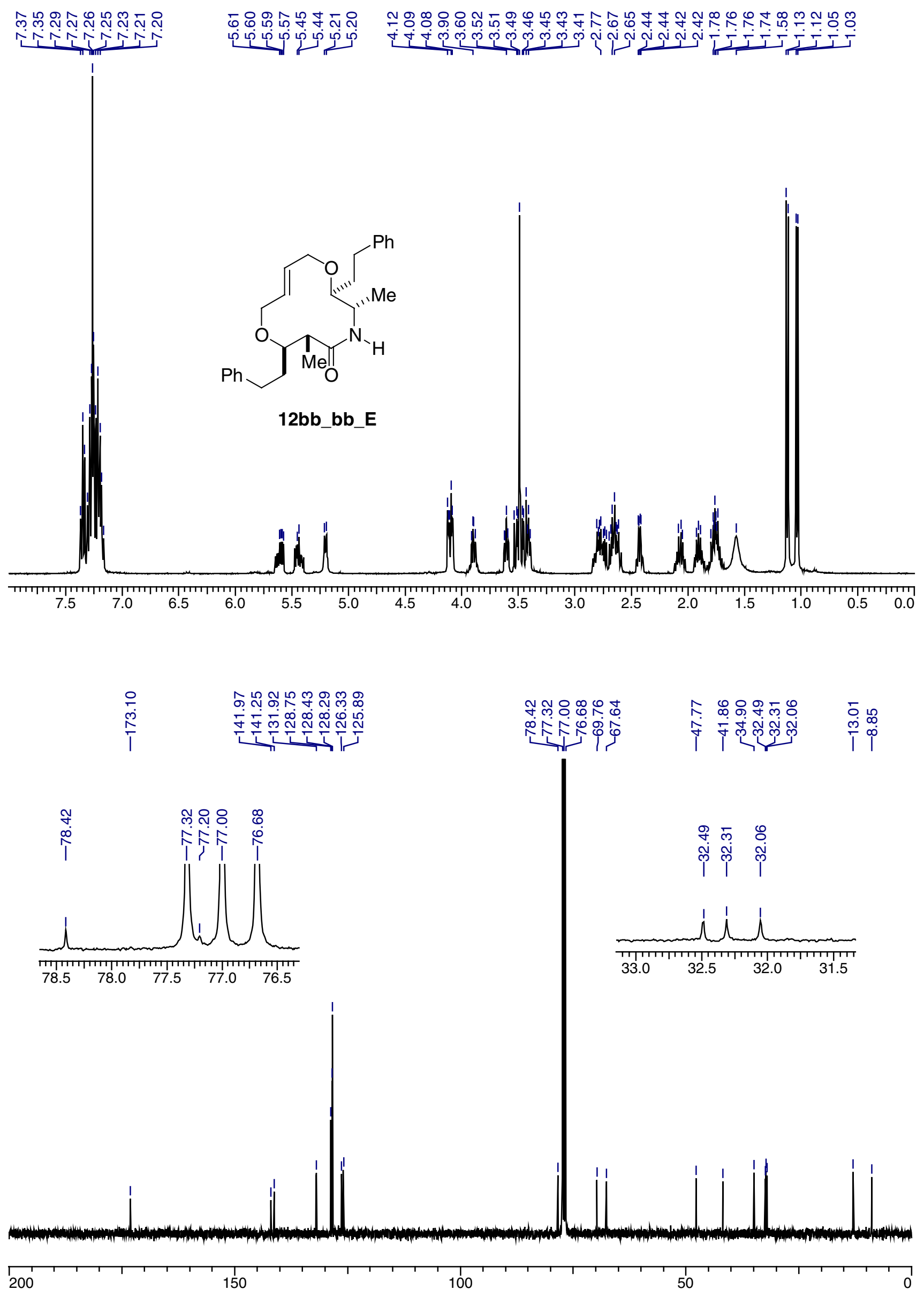

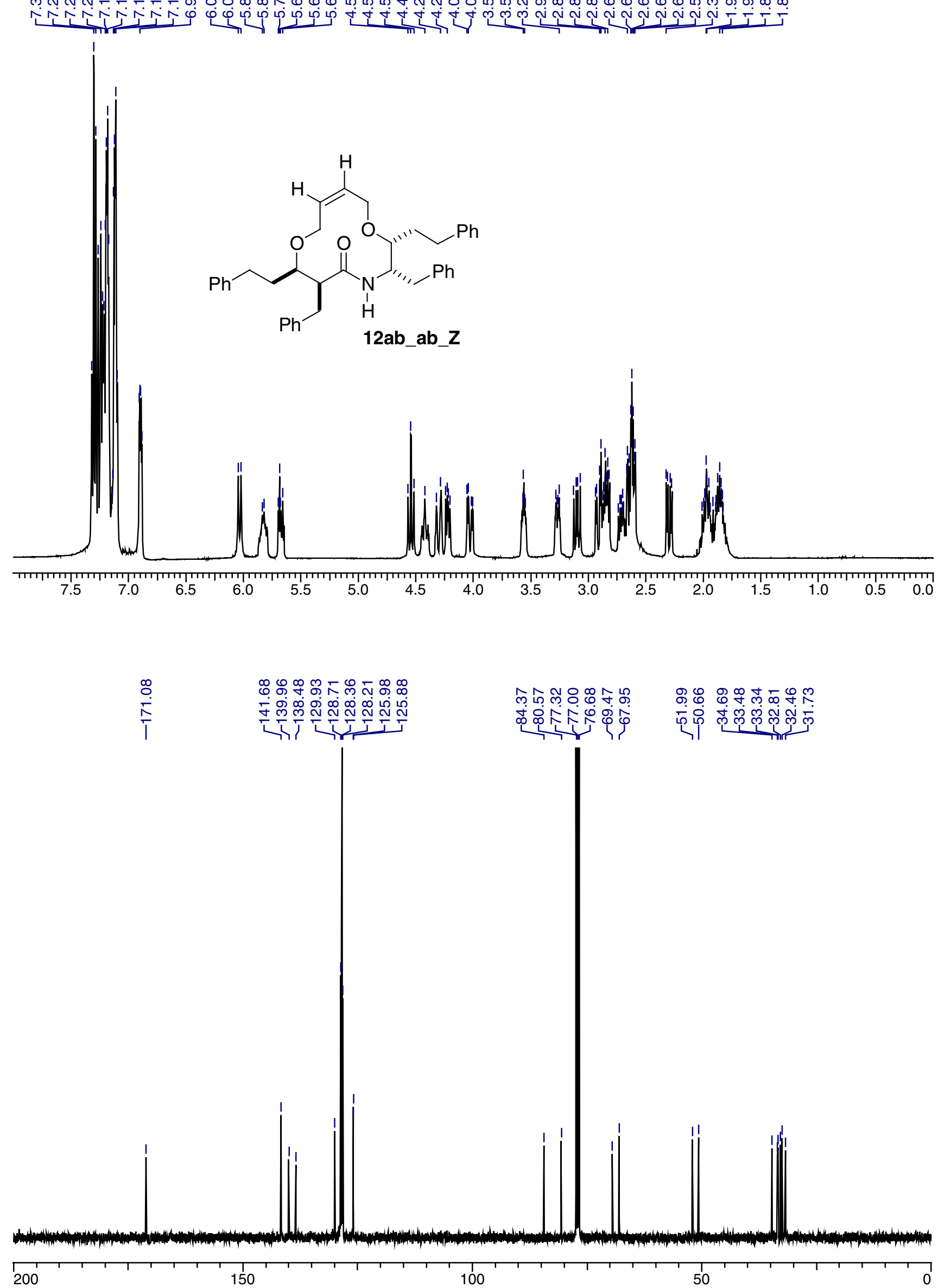


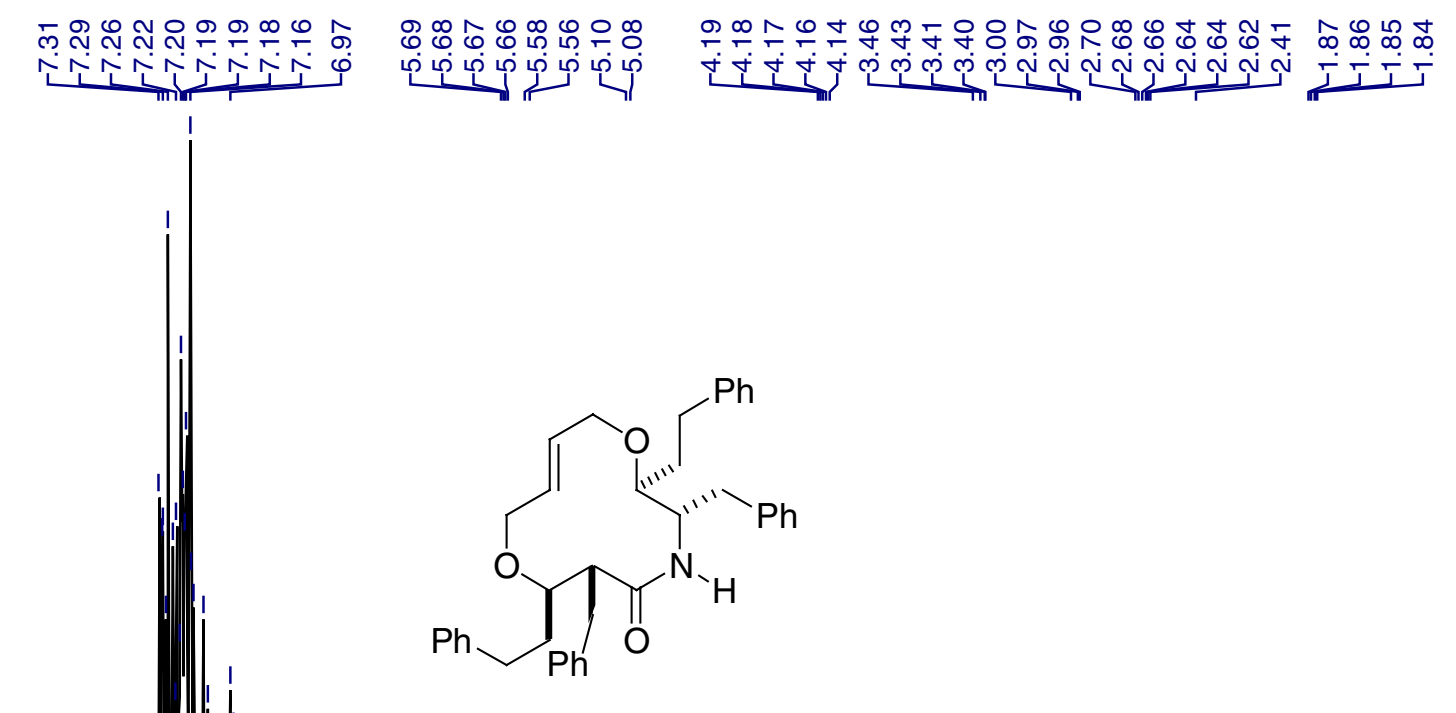

$$
\text { 12ab_ab_E }
$$
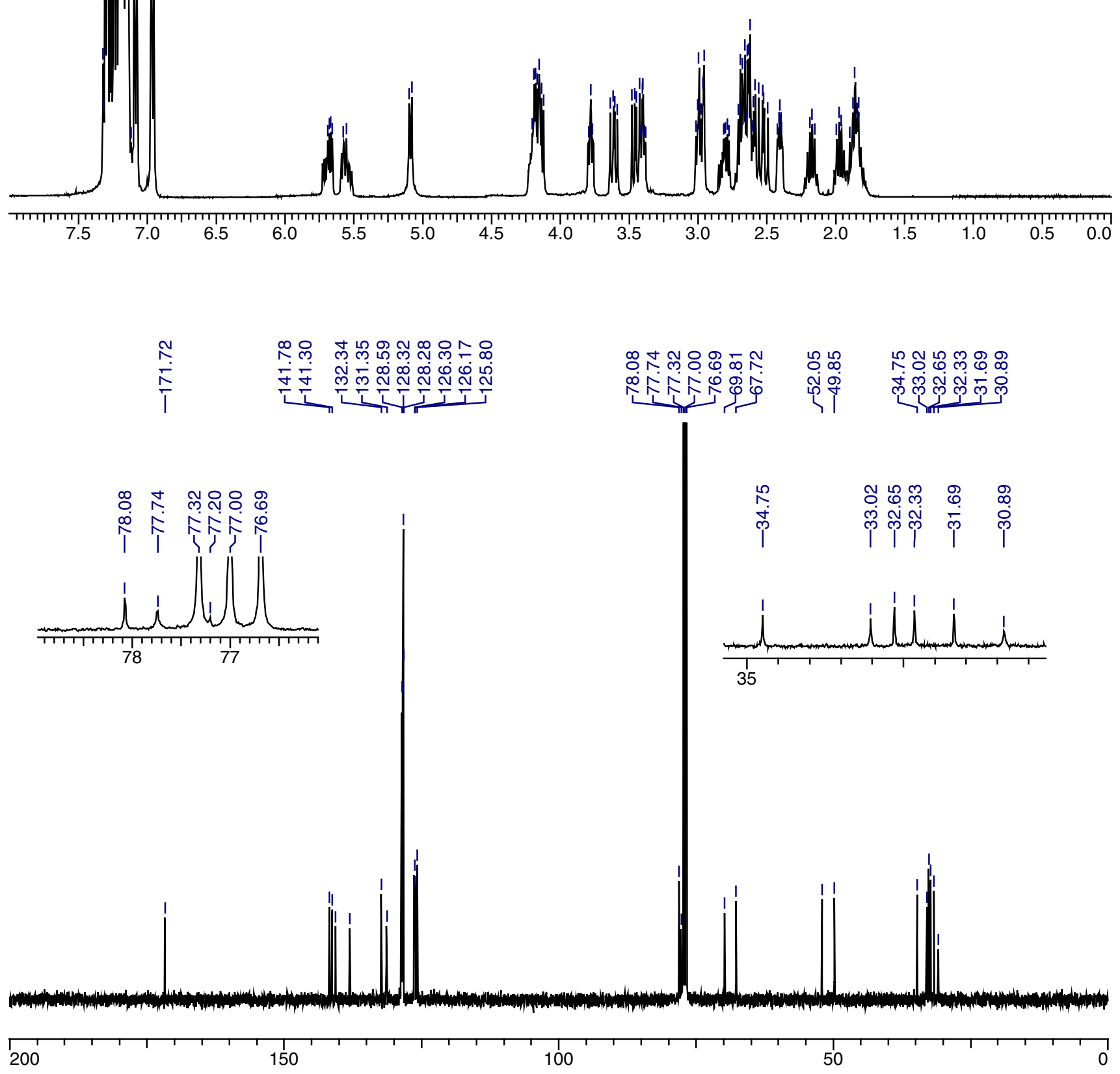

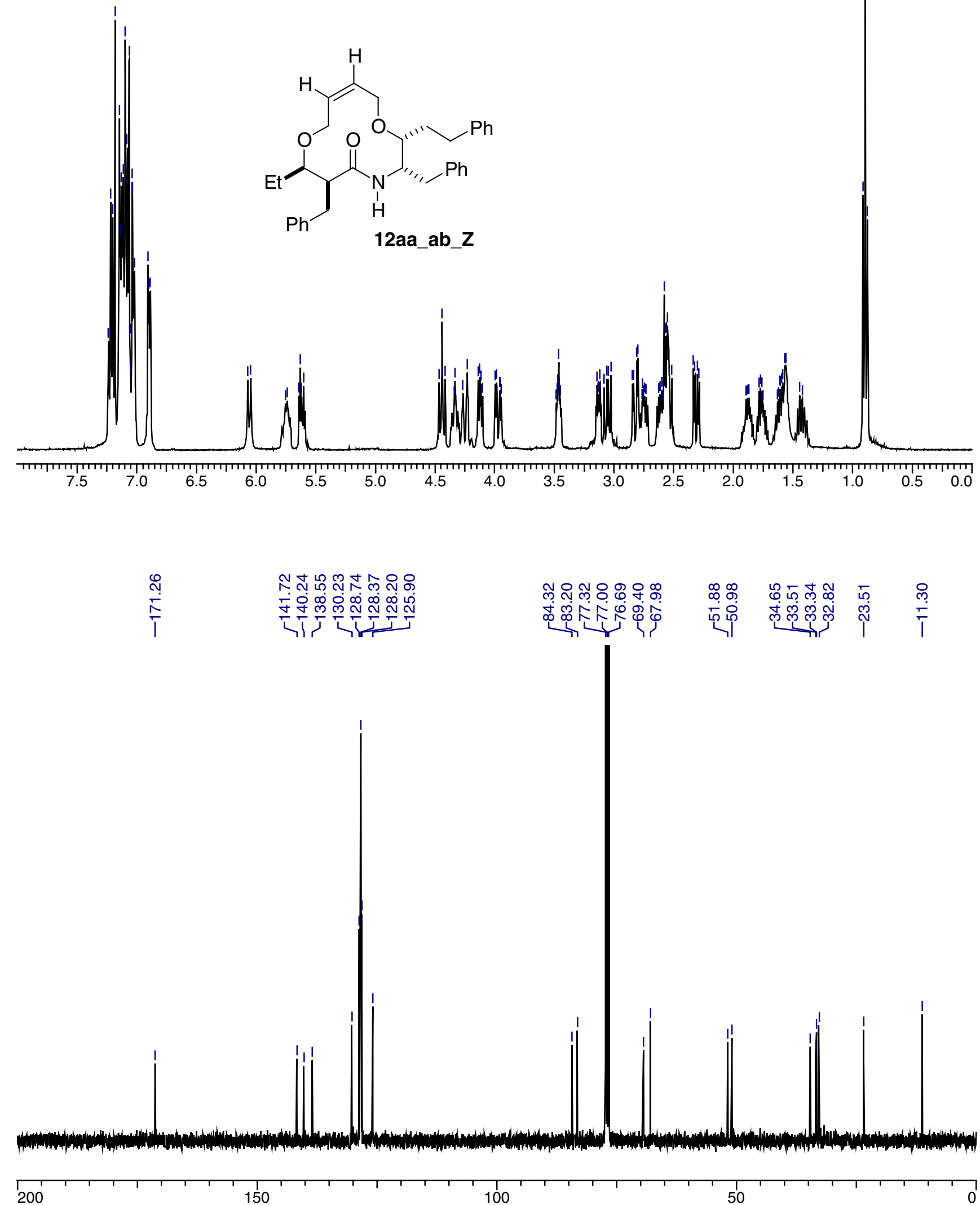

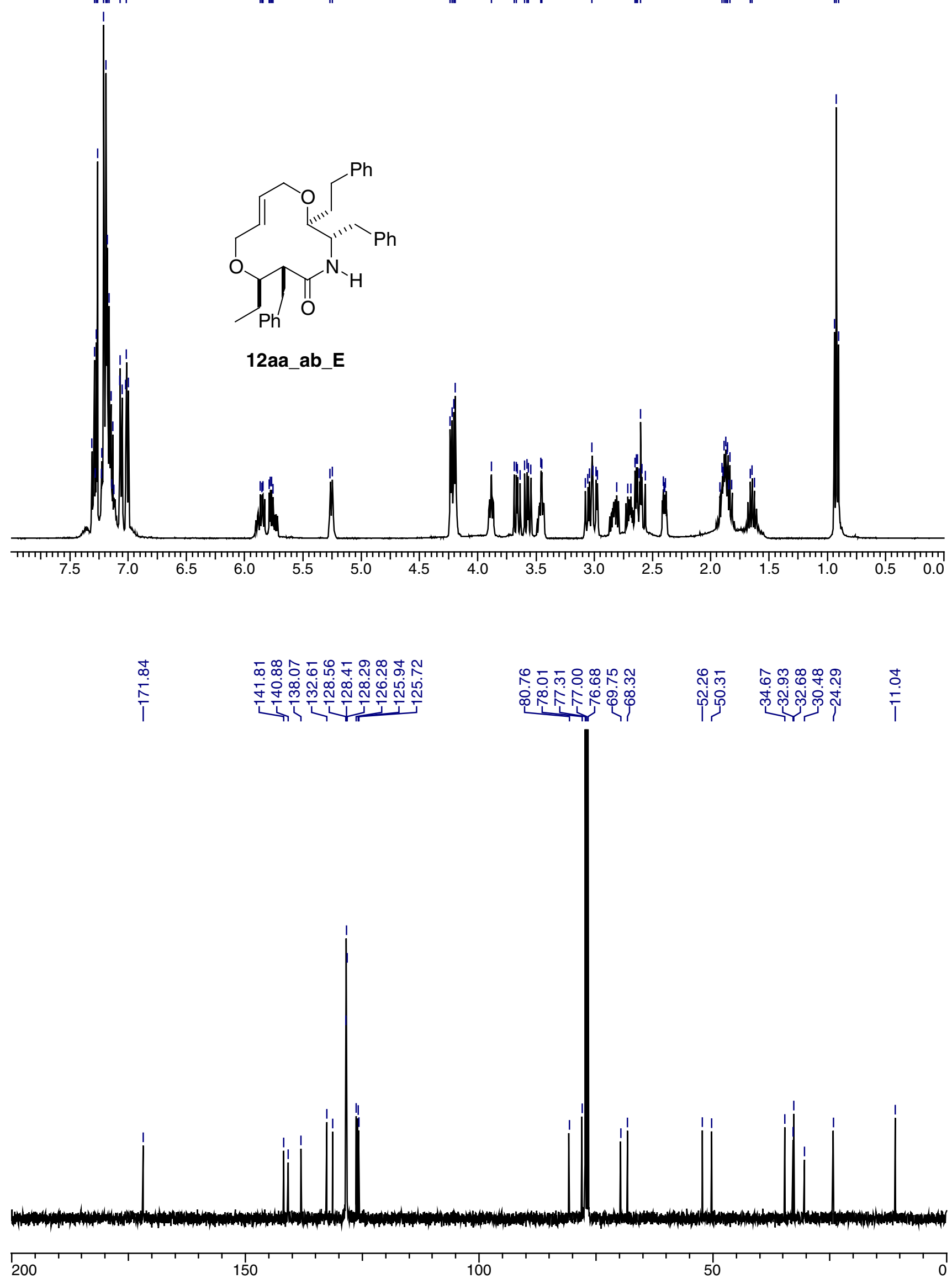


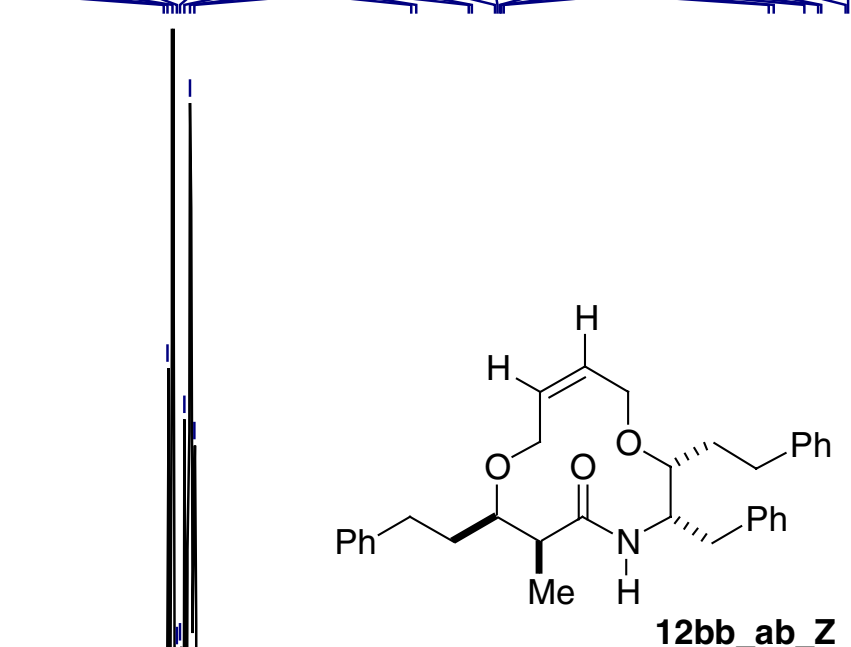

12bb ab $Z$

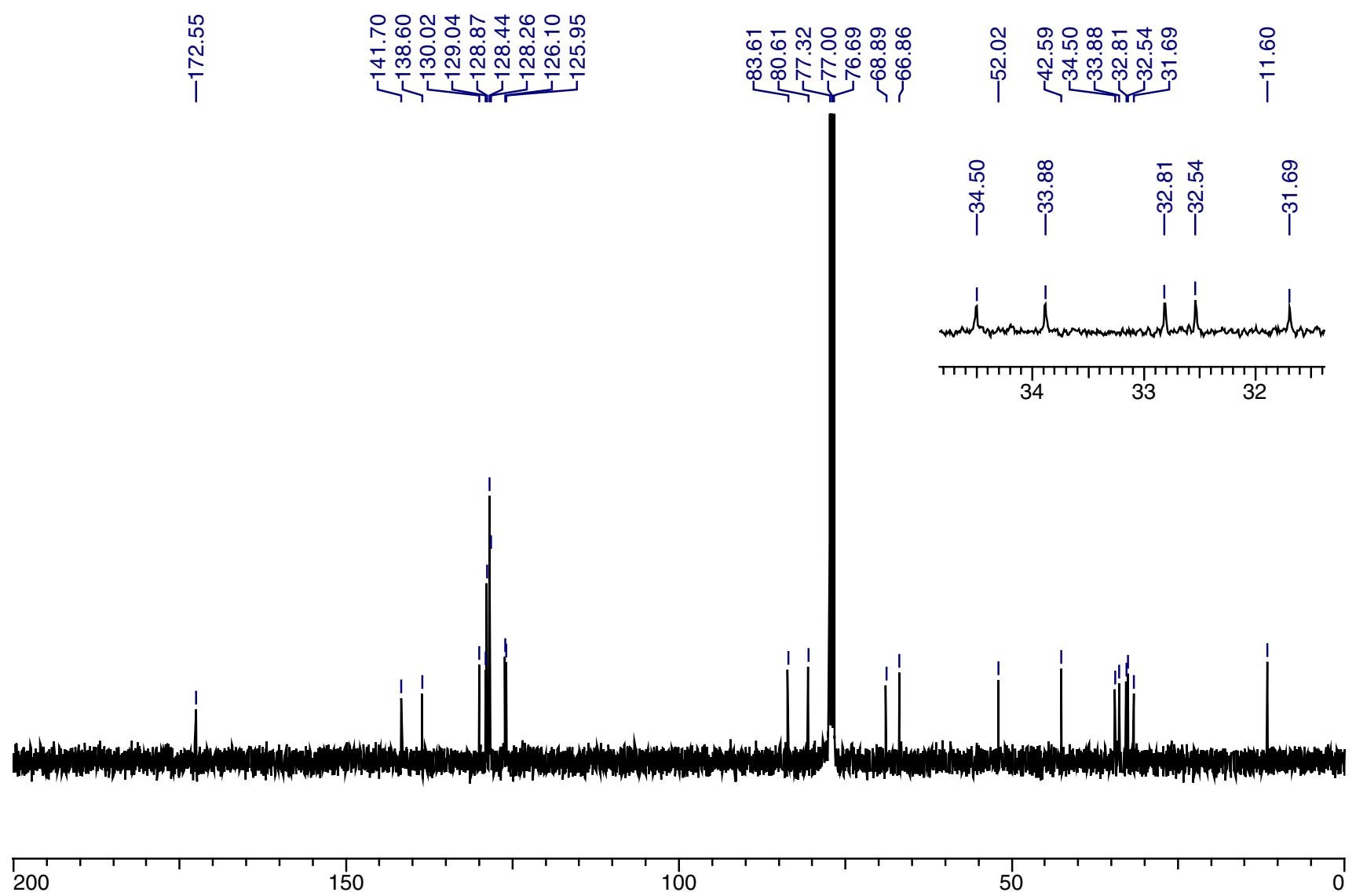




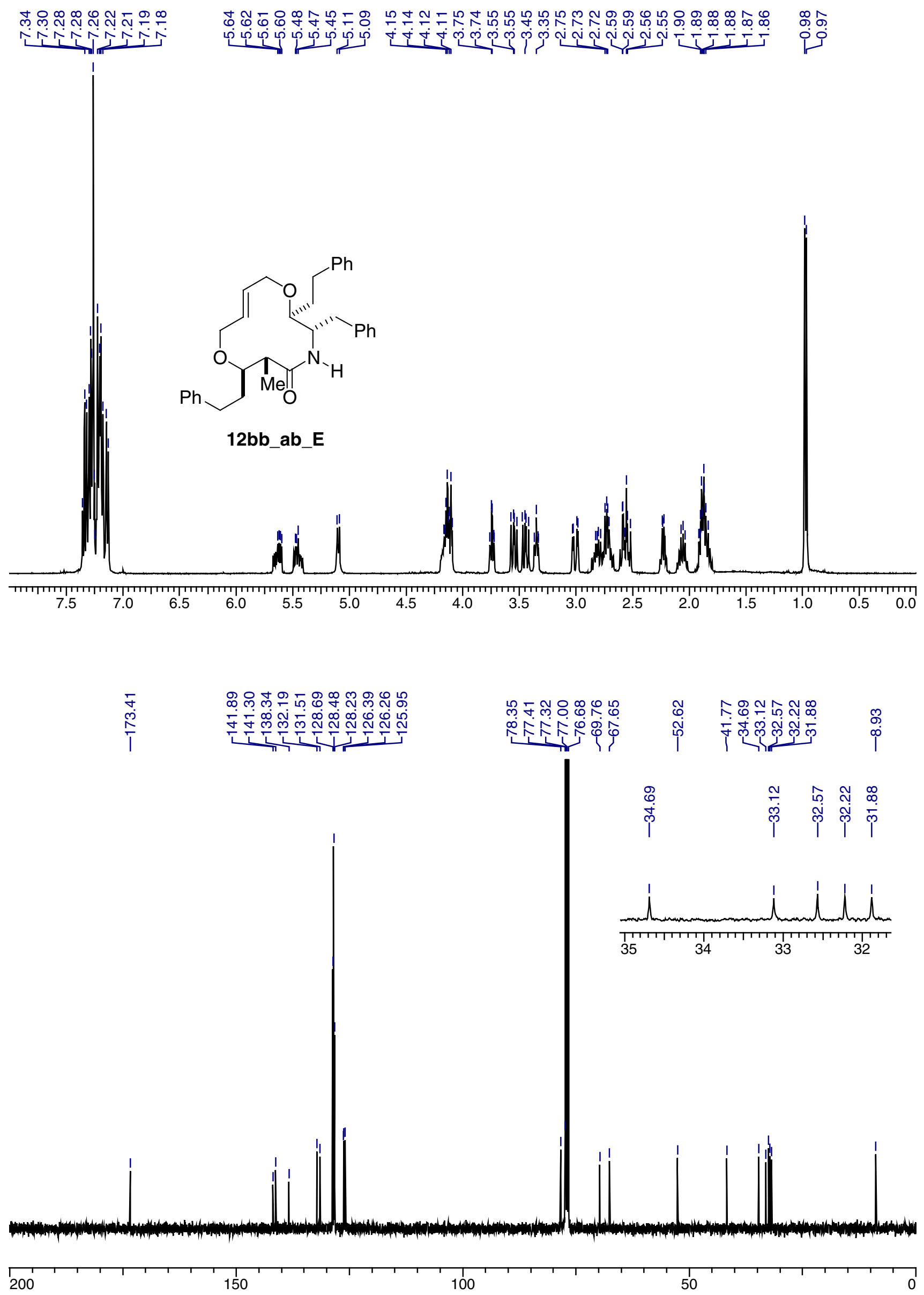



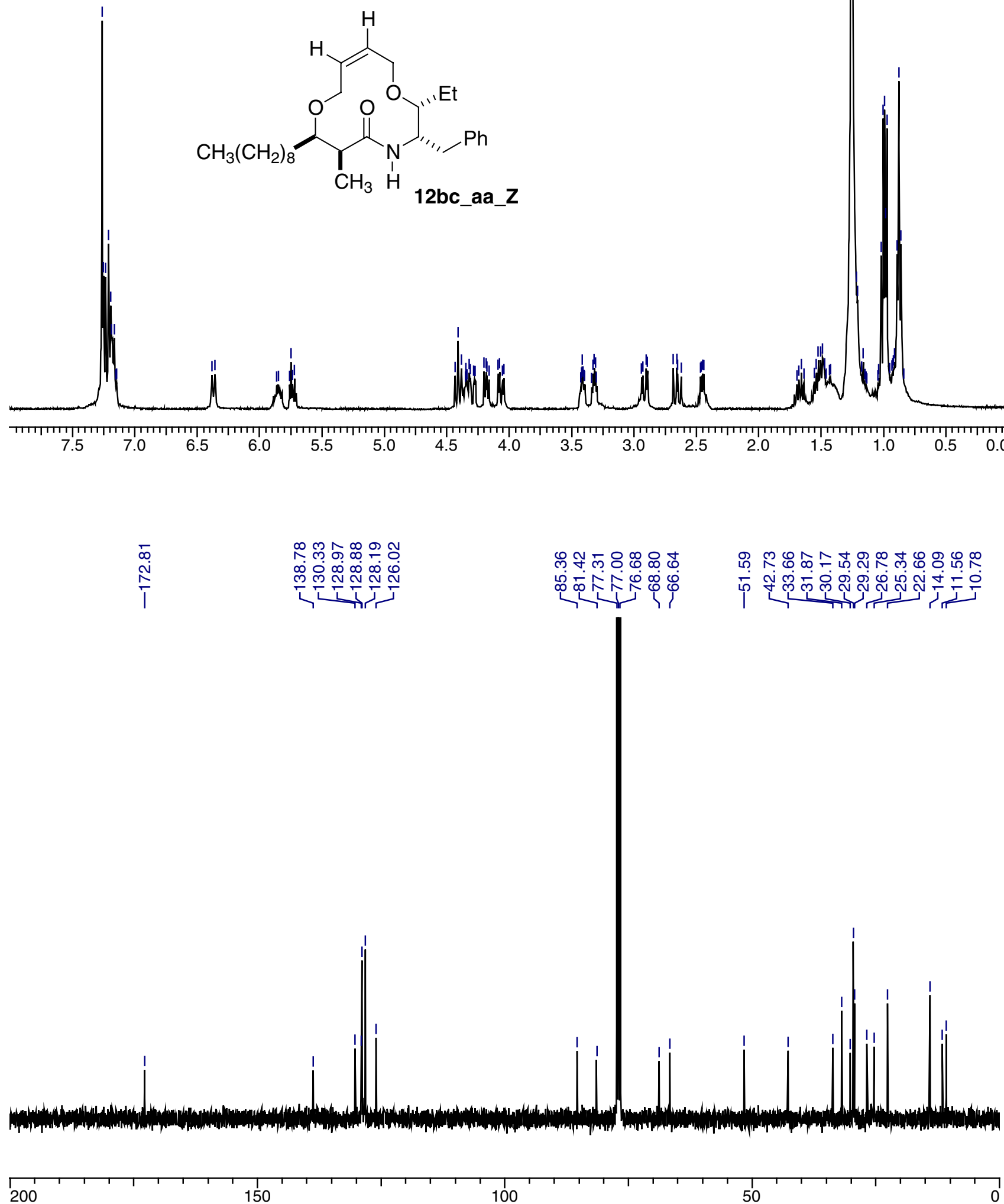

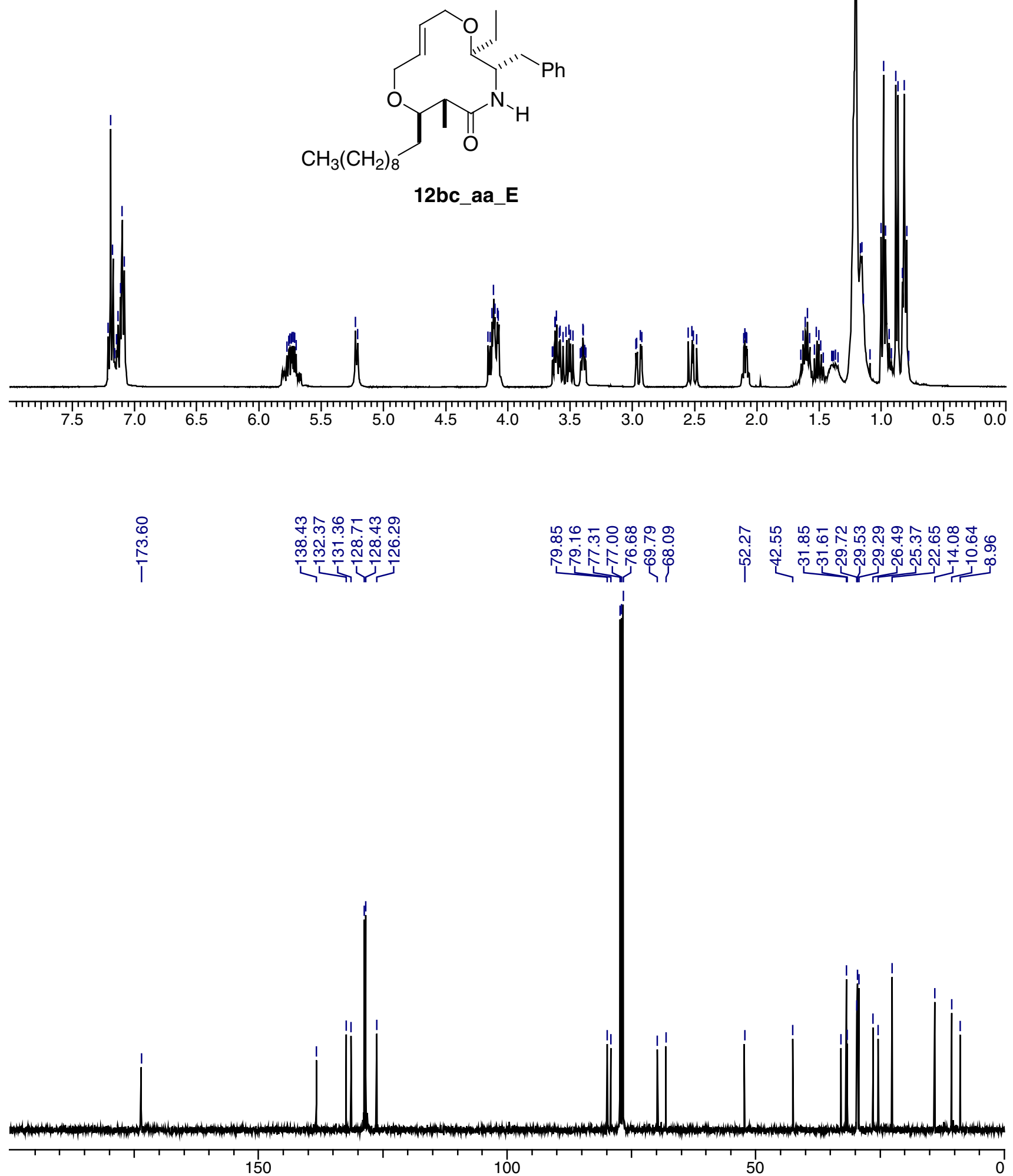


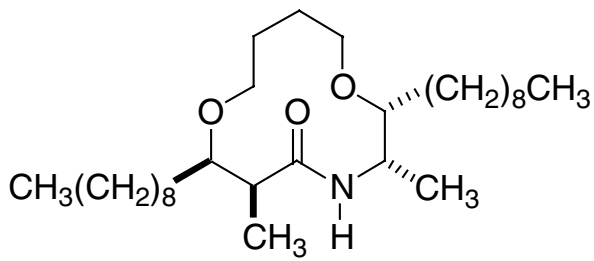

24bc_bc
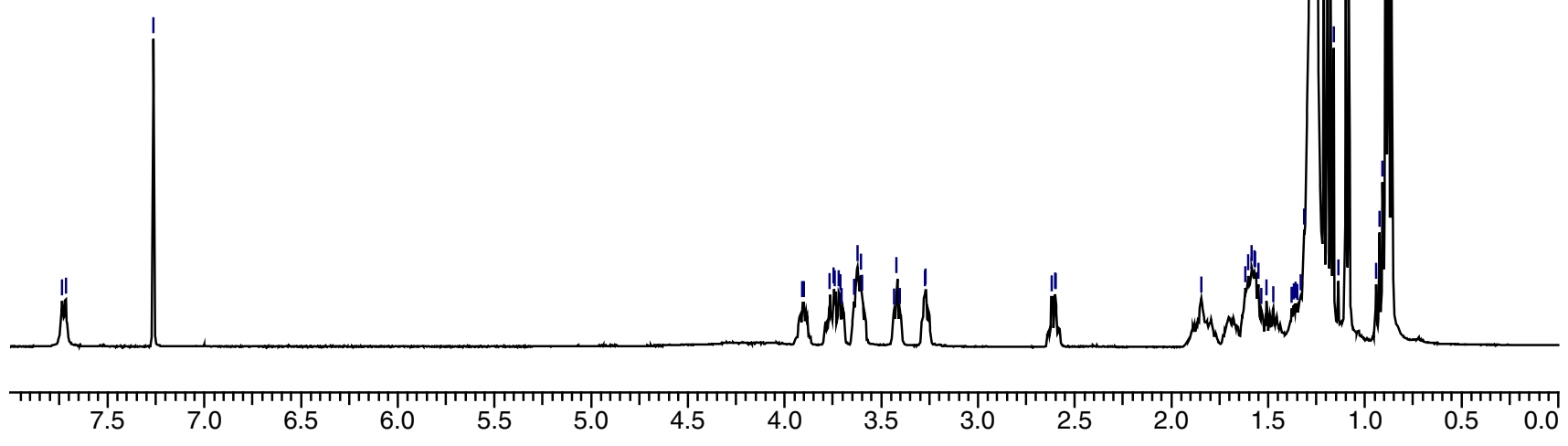

$\frac{\text { N }}{\stackrel{N}{\mathfrak{N}}}$
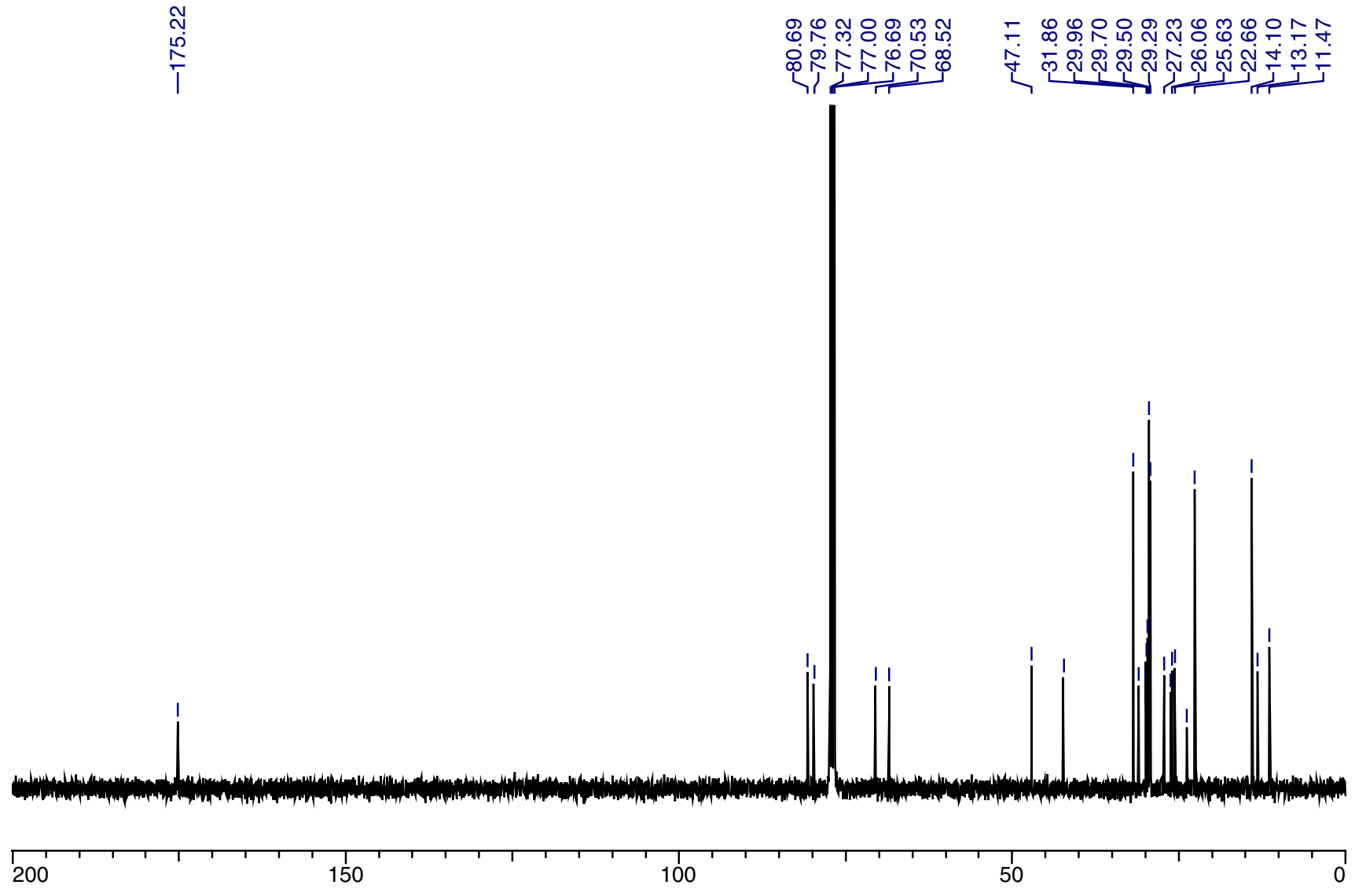